\title{
Urban Heat Island Intensity in London: An investigation of the impact of physical characteristics on changes in outdoor air temperature during summer.
}

\author{
Authors \\ Maria Kolokotroni and Renganathan Giridharan \\ Mechanical Engineering, School of Engineering and Design, Brunel University, \\ Uxbridge, UB8 3PH, UK \\ Email: giridharan.renganathan@brunel.ac.uk
}

\begin{abstract}
:
The study looks at the potential of physical characteristics in mitigating the Urban Heat Island Intensity (UHI) in London during summer. This research uses six on-site variables namely aspect ratio, surface albedo, plan density ratio, green density ratio, fabric density ratio and thermal mass for the investigation in six data sets. The climatic variations in summer are controlled by classifying the data into clear sky, partially cloudy and cloudy periods. Geographical variation is controlled by classifying the data into core, urban and semi urban areas. Maximum daytime UHI of $8.9^{\circ} \mathrm{C}$ is found in semi-urban area during partially cloudy period while maximum nocturnal UHI of $8.6^{\circ} \mathrm{C}$ is found in urban area during clear sky period when the wind velocity is below $5 \mathrm{~m} / \mathrm{s}$. The most critical climate and geographical location in determining the changes in outdoor air temperature in London are partially cloudy periods and urban areas respectively. Among the variables studied, most critical
\end{abstract}


variable that determines the daytime and nocturnal changes in outdoor air temperature is surface albedo.

Keywords: Urban heat island intensity (UHI); clear sky period; partially cloudy period; cloudy period; core are; urban area; semi-urban area, on-site variables.

\section{Introduction}

Most cities around the world face undesirable thermal impacts due to fast decline in natural land surfaces (Oke, 1987; Santamouris, 2001a). This is largely due to rapid urbanization. Changes in urban surfaces have altered the radiative, thermal, moisture and aerodynamic properties of the environment (Oke, 1987; Givoni, 1998; Giridharan et al, 2007a). This has caused concentration of heat in urban areas compared to surrounding rural areas, and this phenomenon is known as urban heat island intensity (UHI) which has caused alarming effects in many cities (Givoni 1998; Macgregor and Niewolt, 1998, Santamouris 2007a).

Research studies have confirmed the extent of UHI within many cities in Europe (Cartalis et al 2001, Santamouris 2007b). Studies have also confirmed the impact of the UHI on energy demand by buildings in hot climates in Europe (Santamouris et 2001b, Hassid et al 2000). Recent UHI studies conducted in London indicate that urban population could be affected severely in terms of energy consumption and health, especially in summer if the current urbanisation trend continues (Kolokotroni et al, 2006; GLA, 2006). First person to indicate the presence of UHI in London was Luke Howard as reported by Landsberg, (1981). At the turn of the $19^{\text {th }}$ Century, he discovered -0.2 and $2.0^{\circ} \mathrm{C}$ during daytime and night respectively. Mid 60's to early 
80's researchers such as Chandler (1965) and Landsberg (1981) carried out notable studies on London UHI and indicated the presence of UHI in the order of 4 to $6^{\circ} \mathrm{C}$ during night. In 1999 and 2000, extensive field measurements were carried in London and results indicated the presence of UHI as high as $7^{\circ} \mathrm{C}$ (Watkins et al, 2002a). The work so far focused on the UHI in relation to energy demand by buildings. In papers published already, the average variation of air temperature has been indicated during the summer months for specific times and on average (Graves et al, 2001; GLA, 2006) as well as the strong correlation between UHI and distance from the London centre (Watkins et al, 2002a). In addition, the effect on passive design and in particular night ventilative cooling (Kolokotroni et al, 2006) and cooling (and heating) energy demand have been investigated (Kolokotroni et al, 2006 \& 2007; Watkins et al, 2002b). Some indications of the additional effects of urban physical characteristics such as urban canyon geometry, albedo and vegetations has been identified in published articles but has not been studied in detail until now (Kolokotroni et al, 2007; Watkins et al, 2007) .

This paper continues the work by investigating the impact of physical characteristics on changes in outdoor air temperature of London during the summer months while controlling the geographical and climatic changes. The analysis is broadly divided into trend and regression analysis of daytime and nocturnal data. Both on-site and offsite variables will influence the changes in the outdoor air temperature (Giridharan et al, 2007a). The immediate and frequent changes are caused by on-site variables while off-site variables represent the macro level environmental changes over a long period; for example surface albedo is an on-site variable while location quotient is an off-site variable. This paper will limit its regression analysis to on-site physical variables due 
to logistical and resource constraints while off-site variables as well as UHI during the heating season is the subject of continuing further work.

\section{Controlling and selection of variables}

The time and space as a function of meteorological, geographical and urban characteristics will determine the extent of UHI of a particular environment (Oke, 1987; Golany, 1996, Livada et al, 2002). Considering the complex variations in seasonal (meteorological) and geographical variables in different environments, it is important to control seasonal and geographical variables as much as possible to understand the location specific impacts on changes in outdoor air temperature (Giridharan et al, 2007a and 2007b). This paper reports on work in which the seasonal variation was broadly controlled by focusing on the summer period (May to September) in London. In temperate climates, May to September is usually specified as the cooling period for many applications as for example the determination of cooling loads for buildings. This period includes the highest solar radiation intensity (June) and the highest air temperatures (July-August). Further, more specific controls within the summer are considered in terms of sky conditions and wind.

Sky conditions were classified into three categories; clear-sky (CSP), partially-cloudy (PCP) and cloudy periods (CP) as defined in Table 1. The classification range was worked out based on similar studies conducted in other parts of the world (Giridharan et al 2007a; Lam, 1998). It adapts from the official classification of skies for daylighting calculations according to CIE to reflect prevailing conditions in London. 
According to CIE, clear sky has less than $30 \%$ cloud cover, partly cloudy sky has between $30 \%$ and $70 \%$ and cloudy sky has more than $70 \%$ cloud cover.

London sky is characterised by very regular overcast conditions (cloud cover 7-8 octas for more than $55 \%$ of the hours in the summer of 2000) and this was taken into account in this classification. For the classification in this paper, CSP sky model includes all hours during which the cloud cover ranges between 0 and 3 oktas (approximately 15\% of all hours in the summer of 2000). For these conditions global solar radiation intensity during the day is more than $500 \mathrm{~W} / \mathrm{m}^{2}$. PCP sky includes all hours which the cloud cover ranged between 4 and 6 oktas (approximately 27\% of all hours in the summer of 2000). The solar radiation intensity ranges between 300 and $500 \mathrm{~W} / \mathrm{m}^{2}$. CP sky includes all hours during which the could cover was 7 to 8 oktas and this accounted for approximately $58 \%$ of all hours; in this case the global radiation intensity was less than $300 \mathrm{~W} / \mathrm{m}^{2}$ during the day. For the analysis, day time classification mainly follows the solar radiation intensity while the night time classification follows the cloud cover. The climatic conditions of London according to this classification are summarised in Table 2 separately for day and night.

Three meteorological wind ranges were defined as below $10 \mathrm{~m} / \mathrm{s}$, below $5 \mathrm{~m} / \mathrm{s}$ and below $2.5 \mathrm{~m} / \mathrm{s}$. This study considers wind velocity data from Heathrow meteorological station. Therefore, on most occasions, at any location under this study, one could expect lower wind velocity than what is specified above.

The geographical variations in London are controlled by classifying the data into core, urban and semi urban as shown in Table 3. The categorisation of geographical zones mainly follow the distance from the centre of London as distance has been identified 
as one of the main parameters influencing UHI (Kolokotroni et al, 2007; CIBSE, 2006). This has been conformed by extensive site visits to identify the development pattern, buffer zones, density of development etc.

The on-site variables selected for this research work are aspect ratio, plan density ratio, green density ratio, fabric density ratio, surface albedo and thermal mass (Table 4). These variables are selected based on the research findings of Graves et al (2001), Kolokotroni et al $(2006,2007)$ and GLA (2006). Selection of variables was also guided by similar research work done in different parts of the world to study the impact of on-site variables on UHI (Giridharan et al, 2007a; Shashua-Bar and Hoffman, 2003; Swaid and Hoffman, 1990a-b; Bottyon and Unger, 2001; Wienert and Kuttler, 2001). The selection is also informed by models developed using Artificial Neural Network techniques (Mihalakakou et al 2002 and 2004, Santamouris et al 1999). Some of the on-site meteorological variables such solar radiation intensity and wind velocity could not be considered due to practical limitations in measuring these parameters over a long time. The limitation on analysis in the absence of such data will be addressed in the discussion section.

The dependent variable for the analysis is urban heat island intensity (UHI). The UHI is defined as the air temperature difference between a location within the city and a reference rural location at a specific time. The UHI in this research is the air temperature difference between a specific station in London area and Langley measurement station (reference station) at a given time. Predominant wind direction in summer is from west. Langley is a large park located far west of London (Fig.1). 


\section{Data measurements and observation}

The field measurements were carried out in 80 locations covering eight transects

(Fig.1). A detail description on measurement locations is presented in the research work done by Watkins (2001) and Kolokotroni et al (2006). At all these locations, hourly basis data was collected using Tinytalk loggers mounted on lamp post at a height approximately $6 \mathrm{~m}$ above the ground. The Tinytalk was placed inside a white painted solar shield. The $6 \mathrm{~m}$ height was selected largely on security concerns and restrictions imposed by the local authorities. Ideally, measurements should be carried out at $2 \mathrm{~m}$ intervals from the ground; if only one measuring point is possible then a height of 1.5 to $2 \mathrm{~m}$ would be sufficient for thermal comfort assessments while for energy consumption calculations, measurement in mid range of the surrounding building height would be more representative of the temperature variations. The height of $6 \mathrm{~m}$ selected in this study was a compromise but suitable enough to indicate the changes in outdoor air temperature within most of the urban canyons in London in particular within the core area (Kolokotroni et al 2006).

The data for independent variables are sourced from literature and institutional information (Table 4). Similar approach was successfully used by Giridharn et al (2004) for the preliminary UHI research work in Hong Kong. This research considers $50 \mathrm{~m}$ radius with respect to the measurement point as the study area i.e. the environmental area. In Hong Kong, 15 to $17 \mathrm{~m}$ radius is considered appropriate for urban climate studies (Giridharan et al, 2007a-b). But in Brazil, 150m radius is considered as suitable micro environment area for urban climate studies (Costa et al, 2007). For London, changes in temperature at different location and fabric pattern, 
especially aspect ratio, suggests $50 \mathrm{~m}$ radius with respect to the measurement point as appropriate area to study the climate variations. In the case of specific heat capacity and surface albedo, weighted average is taken to incorporate the variation in the surface materials within the environmental area of the respective measurement point.

\section{Analysis}

The analysis is carried in two stages. The first stage focuses on the trend analysis while second stage deals with the regression analysis. Each of these stages will have separate day and nocturnal analysis. This study considers 7:00hrs to 17:00hrs as daytime while 18:00 hrs to 6:00hrs as nocturnal. The trend analysis will facilitate to understand the UHI pattern in each of the controlled segments. Further it will assist to focus on regression analysis with appropriate data set. On most occasions, the critical discussions will be limited to wind velocity below $5 \mathrm{~m} / \mathrm{s}$. The ideal condition to observe UHI is under calm wind (i.e. wind speed less than $5 \mathrm{~m} / \mathrm{s}$ ) and clear skies (Oke, 1987).

The regression analysis will discuss the impact of 6 on-site variables (Table 4) on day time and nocturnal UHI. Initially, the regression analysis will focus on three climate categories (Table 1) to select the critical climate period. Then, the analysis will focus on three geographical zones (core, urban and semi-urban) within the critical climate category. The level of significance for the study is set at $5 \%$. Most of the data for independent variables are non-parametric nature, therefore results should be observed within this perspective. 


\subsection{Stage-1}

\section{1 .1 Daytime trend analysis}

The mean daytime UHI during clear-sky, partially-cloudy and cloudy periods remain same $\left(1.1^{\circ} \mathrm{C}\right)$ when the wind velocity influence is not controlled. This shows the importance of controlled analysis. In the absence of controlled analysis, one could under estimate daytime UHI in London. Daytime UHI trends (Fig. 2a) in the absence of wind control follow the accepted premises from May to July. But from July onwards UHI during clear-sky periods is lower than partially-cloudy and cloudy periods. This could be largely attributed to rainfall rather than solar radiation and wind velocity. Especially, solar radiation intensity needed to be discounted for the cause since it is much higher during clear-sky periods than partially cloudy and cloudy periods of summer daytime. Comparison of precipitation between early months of the summer (May to mid July) and late summer (mid July to September) were made for the summer of 2000 based on met data provided for Heathrow. The comparison concluded that the precipitation levels during the later part of the summer in 2000 were much higher than the early part (70mm of rainfall for May to mid July against $110 \mathrm{~mm}$ for mid July to September during the day). In addition, normally clear sky days come following the rainy days. Therefore one could expect cooling due to evaporation to be high during clear sky periods. This has resulted in the drop in UHI during clear-sky period of later part of the summer. It is important to note that, during August, mean UHI $\left(1.0^{\circ} \mathrm{C}\right)$ on clear-sky periods when the a wind velocity is below $2.5 \mathrm{~m} / \mathrm{s}$ is lower than mean UHI $\left(1.2\right.$ to $\left.1.4{ }^{\circ} \mathrm{C}\right)$ on partially cloudy and cloudy periods when the wind velocity is below $10 \mathrm{~m} / \mathrm{s}$ (Fig. 2b-d). This indicates, especially in August when rainfall is above average $(26 \mathrm{~mm}$ of rainfall for August against $10 \mathrm{~mm}$ 
rainfall in June during the day), London could be warmer during partially cloudy and cloudy periods than clear sky periods. At the same time, maximum daytime UHI during clear-sky, partially-cloudy and cloudy periods are $7.4,8.9$ and $8.8{ }^{\circ} \mathrm{C}$ respectively when the wind velocity is below $5 \mathrm{~m} / \mathrm{s}$. In general the partially cloudy periods, especially during later part of the summer, rises outdoor air temperature much more than any other periods in the summer.

During daytime, irrespective of the climate variations, semi-urban (zone-3) area produces the maximum UHI (Table 5). Literature suggest to have the maximum daytime UHI in semi urban (zone-3) area during clear sky periods while Core (zone1) area to have the maximum during other two periods, especially during cloudy periods, due to trapping of long wave radiation. But, on most occasions, during the daytime, semi urban area (zone-3) is cooler than core (zone-1) and urban (zone-2) areas irrespective of climate variations. This could be observed both in the monthly (Fig 3a-c) and hourly trends (Fig 4a-c). This phenomenon is acceptable due to density of vegetation, especially density of tree cover in semi urban areas of London. Generally open areas are made of grass lands, and trees with large canopy (25m to $50 \mathrm{~m}$ diameter) and high density of foliage. On most occasions, grass land could account for more than $50 \%$ of the open area. Therefore, maximum UHI in semi urban areas during clear-sky periods could be linked to large grass lands (90\% open to sky) while partially-cloudy and cloudy periods could be linked to high density vegetation locations (trapping of long wave radiation).

At daytime, irrespective of the climate variations on most occasions, urban area. is the hottest place in London, especially in the late afternoon (Fig. 4a-c). This is largely due 
to solar altitude. But, during cloudy periods the variation in UHI at core area and urban area becomes marginal (Fig 4a-b). This could be attributed to characteristics (walling effect) of the core and urban area fabric. Impact of this will be discussed in the section 4.2.1. On the whole, mean UHI values at urban areas during clear-sky, partially cloudy and cloudy periods are $1.7,1.6$ and $1.1{ }^{\circ} \mathrm{C}$ respectively when the wind velocity is below $5 \mathrm{~m} / \mathrm{s}$.

\subsubsection{Nocturnal trend analysis}

The maximum nocturnal UHI during clear-sky, partially-cloudy and cloudy periods are 8.6, 7.3 and $6.6{ }^{\circ} \mathrm{C}$ respectively when the wind velocity is below $5 \mathrm{~m} / \mathrm{s}$ (Table 5). Generally, trend lines of the nocturnal UHI in the absence of wind control are in line with published literature on most occasions (Fig 5a). The over lapping in the clear sky and partially cloudy trend lines could be attributed largely to urban characteristics of London (walling effect etc). But, in all three climate periods, between mid July to mid August, the trends are influenced by the increased rainfall i.e. reference station in the rural setting cools faster. The controlled wind velocity trend lines during clear sky and cloudy periods on most occasions are within the accepted premises but not during partially cloudy period trend (Fig 5b-d). At night, in London, during partially cloudy period wind influence is marginal on most occasions (Fig. 5c). Therefore, substantial amount of changes in outdoor air temperature during partially clouded period could be attributed to the characteristics of London fabric. During both clear sky and cloudy periods, differences in UHI values when the wind velocity is below $5 \mathrm{~m} / \mathrm{s}$ and below $10 \mathrm{~m} / \mathrm{s}$ are marginal. However, when the wind velocity is below $2.5 \mathrm{~m} / \mathrm{s}$ range, $\mathrm{UHI}$ is much higher. This indicates influence of wind velocity above $5 \mathrm{~m} / \mathrm{s}$ on UHI during 
clear sky and cloudy nights is marginal. The impact of wind velocity becomes even more marginalised during partially cloudy periods (Fig. 5c). In this scenario, presence of nocturnal UHI irrespective of the climatic variation could be largely attributed to the characteristics of London fabric.

During night, maximum UHI is found in core area (zone-1) except for clear sky period (Table 6). On clear sky period it was found in urban area (zone-2) station at Fulham Broadway. The high temperature at this point is much to do with the proximity to transport node (anthropogenic heat) rather than geographical location. The investigation on impact of transport node on UHI is beyond the scope of this paper.

At night, core area remains the hottest place during all three climates for the complete summer as expected (Fig 6a-c). Further, hourly trend too shows that at a given nocturnal period the hottest place is core area (Fig 4a-c). Mean nocturnal UHI in core area during clear sky, partially cloudy and cloudy periods were $3.1,2.5$ and $1.8^{\circ} \mathrm{C}$ respectively when the wind velocity is below $5 \mathrm{~m} / \mathrm{s}$. During clear sky and partially cloudy periods the UHI trends of core and urban area remains very similar (frequent fluctuations) as opposed to trend of cloudy periods (fairly flat). This could be observed both in the monthly (Fig 6a-c) and hourly trends (Fig 4a-c), but it is more prominent in the hourly trend. Further, the differences in UHI between core area and urban areas are small compared to differences in UHI between urban and semi urban. But, on cloudy periods, the differences in UHI between core and urban is almost same as the urban and semi urban areas. Further, unlike day time, high and moderate wind velocity trend lines of the respective zones remain close to each other for all three 
climate categories. These issues indicate, first, wind velocity is not the major natural factor in reducing nocturnal UHI at specific climatic zones. Therefore, this could indicate that urbanisation factors contribute to high UHI levels especially in clear sky and partially cloudy periods.

\subsection{Stage-2}

\subsubsection{Regression analysis: impact of onsite variables on daytime UHI}

Table 7 presents the results of 3 daytime climate models. All 6 variables in all 3 models are inline with the accepted trends as indicated in Table 4. However, all 3 models have very low $\mathrm{R}^{2}$. This is an indication that variables selected for this analysis do not explain most of the changes in the daytime outdoor temperature in London. However, "F" static values of all 3 models are higher than the critical values. This is an indication that these three models are stable and consistent in the predictability within the limitations. The models also indicate that variables selected are more suitable to explain the outdoor temperature changes when the impact of solar radiation intensity is of minimum.

In all 3 models, surface albedo is most significant variable. During clear sky periods heat capacity is the second most significant variable while aspect ratio becomes the second most significant variable in other two models. This is acceptable since on clear sky period, the interaction between fabric and solar radiation intensity (short wave) is more prominent while on cloudy periods it is the trapping of long wave radiation by canyon geometry become prominent. Generally, the green density ratio could be 
considered as the $3^{\text {rd }}$ most significant variable. Considering the type and density of vegetation in London, green density ratio should show much higher significant level. The green density ratio may not be the most suitable method to represent the true character of vegetation in London. Further, there is possibility that the vegetation influence being overshadowed by aspect ratio and anthropogenic heat (Giridharan et al, 2007a). The investigation of this issue is beyond the scope of this paper.

Considering the $\mathrm{R}^{2}$, "F" static and the nature of London atmospheric condition (very frequent partially cloudy sky), partially cloudy periods' model could be considered best to explain the changes in outdoor temperature of London. Based on this model, increases in surface albedo, aspect ratio, heat capacity and green density ratio area ratio by $10 \%$ will reduce UHI by $3.0,2.3,2.0$ and $3.8 \%$ respectively. At the same time, increases in plan density ratio and fabric density ratio by $10 \%$ will increase UHI by 1.1 and $0.5 \%$ respectively.

Table 8 presents the daytime regression results of 3 zones during partially cloudy periods. Unlike the above discussed 3 climate models, variables in the zone based models on most occasions are not in line with the accepted premises. Further on most occasions the variables do not appear significant. The $\mathrm{R}^{2}$ and " $\mathrm{F}$ " static values too are very low, especially in the case of core and urban area. This indicates that especially in core and urban areas variables other than what is considered in this research are influential in changing the UHI. Giridharan et al, (2007a-b) have indicated that such influence could come from on-site solar radiation intensity and wind velocity as well as off-site variables such location quotient. 
The semi-urban model has reasonably high $\mathrm{R}^{2}(0.56)$ and "F" static (5.48) value, but variables such as aspect ratio, heat capacity and foot print to environmental area ratio are not in line with the accepted premises. There appears to be a multi colinearity problem between thermal mass and building density ratio. Therefore these two variables show wrong signs for the regression coefficients. On the other hand, aspect ratio shows the positive sign due to lack of variation in the data i.e. semi urban areas of the study, generally have uniform height of terrace housing with marginal variations in the street width. Although daytime zone based models show the tendency to predict, variables and data set needs to be refined and expanded respectively to arrive at tangible results.

\subsubsection{Regression analysis: impact of onsite variables on nocturnal UHI}

Table 9 presents the results of 3 nighttime climate models. Except for foot print to environmental area ratio, all the other variables in all 3 models are inline with the accepted premises as indicated in Table 4. But, when print to environmental area ratio is correlated to UHI, the variable shows the right sign (Pearson correlation coefficient of 0.8 ). Therefore, change in sign of regression coefficient could be due to multi colinearity problem. Such problems are common when the models use institutional data rather than measured data (Giridharan et al, 2007a). But, the influence of this variable on the model is marginal since it has the least significant level in all 3 models. Therefore, the models have the potential for application.

The models have high $\mathrm{R}^{2}$ as well as "F" static. This is an indication that variables used in this study are good indicators for explaining the changes in nocturnal outdoor 
temperature. Unlike the daytime models, $\mathrm{R}^{2}$ of the nocturnal model are very much close to each other. Further, order of the 3 most significant variables, namely surface albedo, fabric density ratio and green density ratio remains same in all three models. The other 3 variables change the order only in the cloudy period model. This is an indication that set of variables selected for the study have the same potential to explain the changes in outdoor temperature irrespective change in nocturnal climate. Strictly speaking, aspect ratio should have been the most significant variable since trapping off long wave plays a major role in nocturnal UHI. But, lack of variation in aspect ratio within the data set could have resulted it to be the $4^{\text {th }}$ most significant variable.

During night, all through all 3 models have high $\mathrm{R}^{2}$, partially cloudy model $\left(\mathrm{R}^{2}=\right.$ 0.79) could be considered as the most accepted model to explain the changes in nocturnal outdoor temperature considering the presence of frequent partially cloudy conditions in London. The nocturnal trend analysis also strengthens this argument (section 4.1.2). According to this model, increases in surface albedo and green density ratio by $10 \%$ will reduce UHI by 4.5 and $1.6 \%$ respectively. At the same time, increases in fabric density ratio, aspect ratio and thermal mass by $10 \%$ will increase UHI by 3.2, 0.6 and $0.5 \%$ respectively.

Table 10 presents the nocturnal regression results of 3 zone based models during partially cloudy periods. Although the 3 models have high $\mathrm{R}^{2}$ and " $\mathrm{F}$ " static, they are not free from multi colinearity problem. In each model, 2 or 3 variables cause the multi colinearity problem. But the correlation coefficients of these variables show the right sign as indicated in Table 4. 
Among the zone based models, the model that is least affected by multi colinearity problem is the semi-urban model. This is established through the checks suggested by Michel (1993). In the semi-urban model, aspect ratio and plan density ratio cause the multi colinearity problem. But, when checked for correlation, both these variables have positive Pearson correlation coefficient of 0.5. This is inline with the accepted premises. Therefore this model has the potential for refinement if appropriate data set is used. The surface albedo emerged as the most significant variable in this model. This is followed by fabric density ratio and green density ratio. This order of significant is same as partially cloudy period nocturnal model (Table 9). Therefore, semi-urban area model of partially cloudy period (Table 10) and cloudy period models (Table 9) are consistent to great extent in terms of behaviour of the variables.

\section{Discussion}

London experiences Urban Cool Islands as well during summer. But the frequency of Urban Cool Island is fairly low. Most of the cool islands are found during late afternoon in the core area. This is largely due to solar altitude and high aspect ratio in London core area. In the night too there are cool islands in core areas but the frequency and number of locations are even lower. Similarly, cool islands are found in urban and semi urban areas too. Further all three climate categories produce Cool Islands. For all practical purpose, urban heat island intensity is the dominant factor during all three climates and at all three geographical locations (Fig 4a-c). 
In the absence of geographical control, mean daytime UHI in London during clear sky, partially cloudy and cloudy periods are $1.3,1.3$ and $0.9^{\circ} \mathrm{C}$ respectively when the wind velocity is below $5 \mathrm{~m} / \mathrm{s}$. On most occasions there are marginal differences in daytime UHI values of clear sky and partially cloudy periods, especially when the wind velocity is below $5 \mathrm{~m} / \mathrm{s}$. At daytime, urban areas (zone-2) are warmer than core (zone-1) and semi urban areas (zone-3), especially during clear sky and partially cloudy days. Mean daytime UHI in urban areas (zone-2), during clear sky, partially cloudy and cloudy periods are $1.7,1.6$ and $1.1^{\circ} \mathrm{C}$ respectively when the wind velocity is below $5 \mathrm{~m} / \mathrm{s}$. Here too there is marginal difference in daytime UHI values of clear sky and partially cloudy periods. Therefore, partially cloudy periods and urban areas are critical to determine the day time UHI in London considering the following;

1. Frequent occurrence of cloudy condition in London

2. Daytime UHI values are relatively high in urban areas during partially cloudy periods

3. Large number people live in the urban area (zone-2).

At night, in the absence of geographical control, mean UHI during clear sky, partially cloudy and cloudy periods are $2.0,1.7$ and $1.0{ }^{\circ} \mathrm{C}$ respectively when the wind velocity is below $5 \mathrm{~m} / \mathrm{s}$. At night, there is a difference $0.3{ }^{\circ} \mathrm{C}$ between clear sky and partially cloudy periods. But, impact of this difference on outdoor comfort and energy consumption levels will be marginal. Therefore, in the absence of geographical control, the impact of clear sky and partially cloudy periods in rising the nocturnal outdoor temperature could be considered of the same order. During night, core area is the hottest place irrespective of climate variation. The mean nocturnal UHI in core area during clear sky, partially cloudy and cloudy periods are $3.1,2.5$ and $1.6{ }^{\circ} \mathrm{C}$ 
respectively when the wind velocity is below $5 \mathrm{~m} / \mathrm{s}$. But, on most occasions, the differences in nocturnal UHI between core and urban area are marginal compared to differences between core and semi-urban area, especially during partially cloudy and cloudy periods. The mean nocturnal UHI in urban areas during clear sky, partially cloudy and cloudy periods are $2.4,2.0$ and $1.3{ }^{\circ} \mathrm{C}$ respectively when the wind velocity is below $5 \mathrm{~m} / \mathrm{s}$. Therefore, urban area (zone-2) could be considered as critical as the core area in determining the nocturnal UHI of London. Considering the London's geography and atmospheric conditions, it is appropriate to focus on urban and partially cloudy period to study the nocturnal UHI.

The daytime partially cloudy period model is the critical daytime climate model. But it has very low $\mathrm{R}^{2}$. This is largely due to the absence on on-site solar radiation intensity measurement and wind velocity. The model could be refined further if it uses more measured data for on-site variables and minimise the institutional data. Similarly, nocturnal partially cloudy period model is the most accepted nocturnal climate model. The plan density ratio variable leads multi colinearity problem in the nocturnal partially cloudy period model. But the influence of this variable on this model is marginal. Therefore, there is very high possibility to refine this model with appropriate data.

The analysis shows that partially cloudy period models (day and night) of urban area have the capacity to predict the changes in the outdoor temperature. But these models are not free from multi colinearity problem. Therefore, future research work should modify the nature of the data and sample size to overcome this problem. Such approach has the potential to develop climate and geographical specific models. 
Among the variables studied, most critical variable to determine the changes in outdoor temperature in London is surface albedo. Other important variables are aspect ratio and green density ratio. The order of significance of these two variables could change if variables such as solar radiation intensity and wind velocity are brought into the model. Further, better results could be achieved if the aspect ratio is replaced by sky view factor. Aspect ratio is a two-dimensional factor and it does not capture the solar radiation influence as the three dimensional sky view factor. Furthermore, green density ratio could be further classified into vegetation above $1 \mathrm{~m}$ height (tree cover) and below 1m height (shrub cover) for achieving better results (Giridharan et al, 2007b).

This study uses wind velocity data from observatory for classification. Therefore, on most occasions, at any location under this study, one could expect much lower wind velocity than what is specified under classification. Our future research work hopes to solve this problem by measuring wind velocity at each location under study. This data will help to refine the regression models as discussed above.

\section{Conclusion}

The study shows that UHI problem is more sensitive in urban areas (zone-2), especially during partially cloudy periods. During partially cloudy periods, in urban areas, maximum daytime and nocturnal UHI are 8.0 and $7.0^{\circ} \mathrm{C}$ respectively when the wind velocity is below $5 \mathrm{~m} / \mathrm{s}$. The changes in outdoor temperature trends in London are within the accepted premises on most occasions. The regression models used in 
this study indicate the capacity to predict the changes in outdoor temperature. Models also indicate that variables selected are more suitable to explain the changes in the out door temperature when the impact of solar radiation on the environment is minimum. But, all the models need refinement in terms of data, sample and variable specifications to create consistency in prediction. Among the variables studied, most critical variable in determining the changes in outdoor temperature for both day and night is surface albedo.

\section{Acknowledgments}

This work is supported by EPSRC (Grant No EP/E016308/1)

\section{References}

Bottyon, Z., Unger, J., 2001. The role of land-use parameters in the development of urban heat island in Szeged, Hungary. $4^{\text {th }}$ Symposium on urban environment (http:// ams.confex.com/ams/AFMAPULE/4urban/program.htm).

Cartalis C., Synodinou A., Proedrou M., Tsangrassoulis A. and Santamouris M., 2001. Modifications in Energy Demand in urban areas as a result of climate changes: an assessment for the southeast Mediterranean region. J. Energy Conversion and Management, 42, 14,1647-1656.

Chandler, T. J.,1965. The climate of London, Hutchinson, London.

CIBSE Guide A., 2006. Environmental Design, UK, CIBSE

Graves, H., Watkins, R., Westbury, P., Littlefair, P., 2001. Cooling Buildings in London - Overcoming the heat island, BR431, CRC.

Giridharan, R., Ganesan, S.,Lau, S.S.Y., 2004. Daytime urban heat island effect in high-rise high-density developments in Hong Kong. Energy and Buildings 36 (6) p525-534. 
Giridharan, R., Lau S.S.Y., Ganesan, S., Givoni, B., 2007a. Urban design factors influencing urban heat island intensity in high rise high density environments of Hong Kong. Building and Environment 42 p3669-84.

Giridharan, R., Lau S.S.Y., Ganesan, S., Givoni, B., 2007b. Lowering the outdoor temperature in high-rise high-density residential developments of coastal Hong Kong: Vegetation influence. Building and Environment (in press).

Givoni, B.,1998. Climate considerations in building and urban design. John Wiley \& sons, USA.

GLA, Greater London Authority (GLA). 2006. London urban heat island (LUHI): A summary for decision makers. UK.

(http://www.london.gov.uk/mayor/environmnet/climate_change/)

Golany, G.S.,1996. Urban design morphology and thermal performance. Atmospheric Environment 30 p455-465.

Hassid S., Santamouris M., Papanikolaou N., Linardi A., Klitsikas N., Georgakis C, Assimakopoulos D.N., 2000. The Effect of the Athens Heat Island on Air Conditioning Load, J. Energy and Buildings, 32,2,131-141.

Kolokotroni, M., Giannitsaris, I., Watkins. R., 2006. The effect of the London heat island and building summer cooling demand and night ventilation strategies. Solar Energy 80 (4) p383-392.

Kolokotroni, M., Zhang, Y., Watkins. R., 2007. The London heat island and building cooling design. Solar Energy 81 (1) p102-110.

Lam. J. C., 1998. Climatic and economic influences on residential electricity consumption. Energy Conservation and Management 39 (7) p623-629.

Landsberg, H.E., 1981. The urban climate. Academic Press. New York.

Livada I., Santamouris M., Niachou K., Papanikolaou N. and Mihalakakou G., 2002. Determination of Places in the great Athens area where the heat island effect is observed. Theoretical Appl. Climatol. , 71, 219-230.

Mcgregor, G. R., Nieuwolt, S., 1998. Tropical climatology. John Wiley \& Sons, New York.

Micheal, S. L. (eds.). 1993. Applied regression: an introduction. In Regression analysis. Sage. USA.

Mihalakakou G., Flocas H.A., Santamouris M. and Helmis C.G., 2002. Application of Neural Networks to the Simulation of the Heat Island over Athens, Greece, Using Synoptic Types as a Predictor. J. Applied Meteorology, 41,5,519-527. 
Mihalakakou G., Santamouris M., Papanikolaou N., Cartalis C. and

Tsangrassoulis A., 2004. Simulation of the Urban Heat Island phenomenon in Mediterranean climates. J. Pure and Applied Geophysics , 161, p.p.429-451.

Oke, T. R., 1987. Boundary layer climates. Methuen, USA.

Santamouris M., Mihalakakou G., Papanikolaou N. and Assimakopoulos D. N., 1999. A Neural Network Approach for Modelling the Heat Island Phenomenon in Urban Areas During the Summer Period. Geophysical Research Letters, 26, 3, p.p. 337340.

Santamouris M. (eds.)., 2001a. Energy and climate in the urban built environment. Earthscan, UK. ch 1,3,4,5,6,7,10,11.

Santamouris M., Papanikolaou N., Livada I., Koronakis I., Georgakis C., Argiriou A. and Assimakopoulos D. N., (2001b). On the Impact of Urban Climate to the Energy Consumption of Buildings, Solar Energy, 70,3,201-216.

Santamouris M., Paraponiaris K., and Mihalakakou P., 2007a, Estimating the Ecological Footprint of the heat island effect over Athens, Greece. Climatic Change, 80 (3/4), pp265-276.

Santamouris, M., 2007b, Heat Island Research in Europe - The State of the Art, Advances in Building Energy Research (ABER) 1 (1), pp123-150, Earthscan.

Shashua-Bar, L., Hoffman, M.E., 2003. Geometry and orientation aspects in passive cooling of canyon streets with trees. Energy and Buildings 35 p61-80.

Swaid, H., Hoffman, M.E., 1990a. Prediction of Urban air temperature variation using the analytical CTTC model. Energy and Buildings 14 p313-324.

Swaid, H., Hoffman, M.E., 1990b. Climatic impacts of urban design features for high and mid latitude cites. Energy and Buildings 14 p313-324.

Watkins, R., Palmer, J., Kolokotroni, M., 2007. Increased Temperature and Intensification of the Urban Heat Island: Implications for Human Comfort and Urban Design, Built Environment, Vol 33 No 1, pp86-96

Watkins, R., Palmer. J., Kolokotroni, M., Littlefair, P., 2002a. The London Heat Island: results from summertime monitoring, Building Serv. Eng. Res. Technol. 23,1 pp. 000-000

Watkins, R., Palmer, J., Kolokotroni, M., Littlefair P., 2002b. The balance of the annual heating and cooling demand within the London urban heat island, Building Serv. Eng. Res. Technol. 23,4 pp. 207-215 
Watkins, R., 2002. The impact of the urban environment on the energy used for cooling buildings. Ph.D. Thesis, Brunel University.

Wienert, U., Kuttler, W., 2001. Statistical analysis of the dependence of urban heat island intensity on latitude. $4^{\text {th }}$ Symposium on urban environment (http:// ams.confex.com/ams/AFMAPULE/4urban/program.htm) 


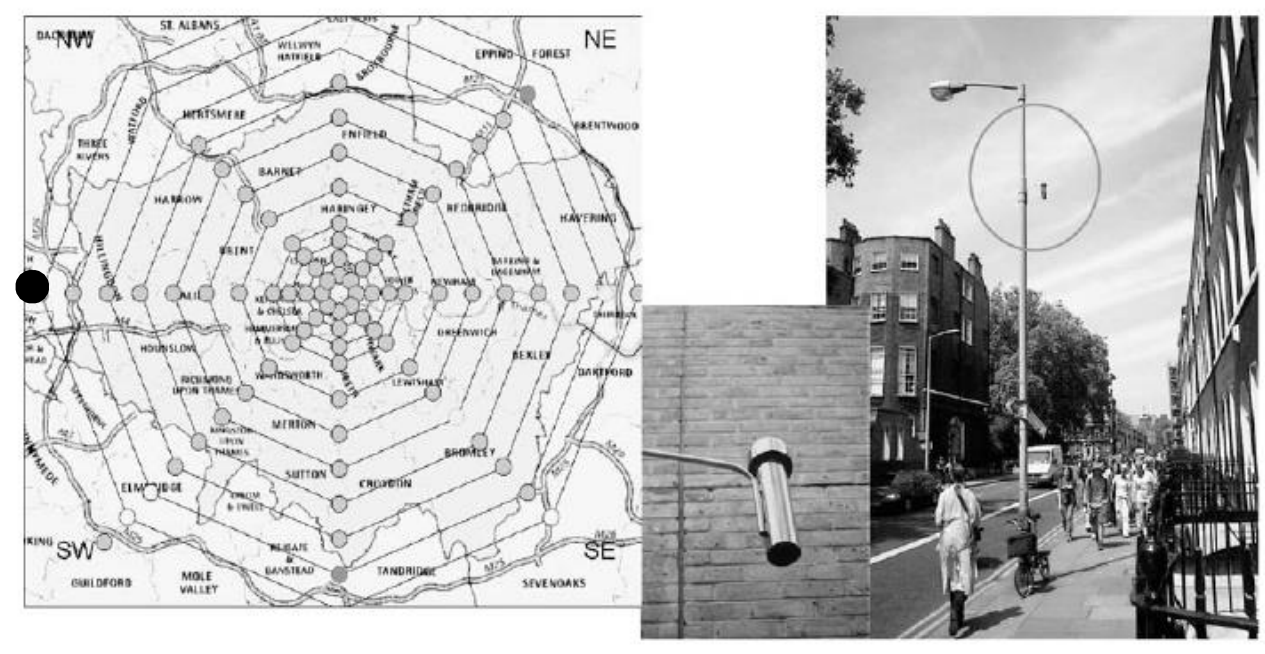

Figure 1: Map of Greater London with air temperature stations (rural location-

Langley- marked) and monitoring equipment mounted in a street near to the British Museum (central London location). 


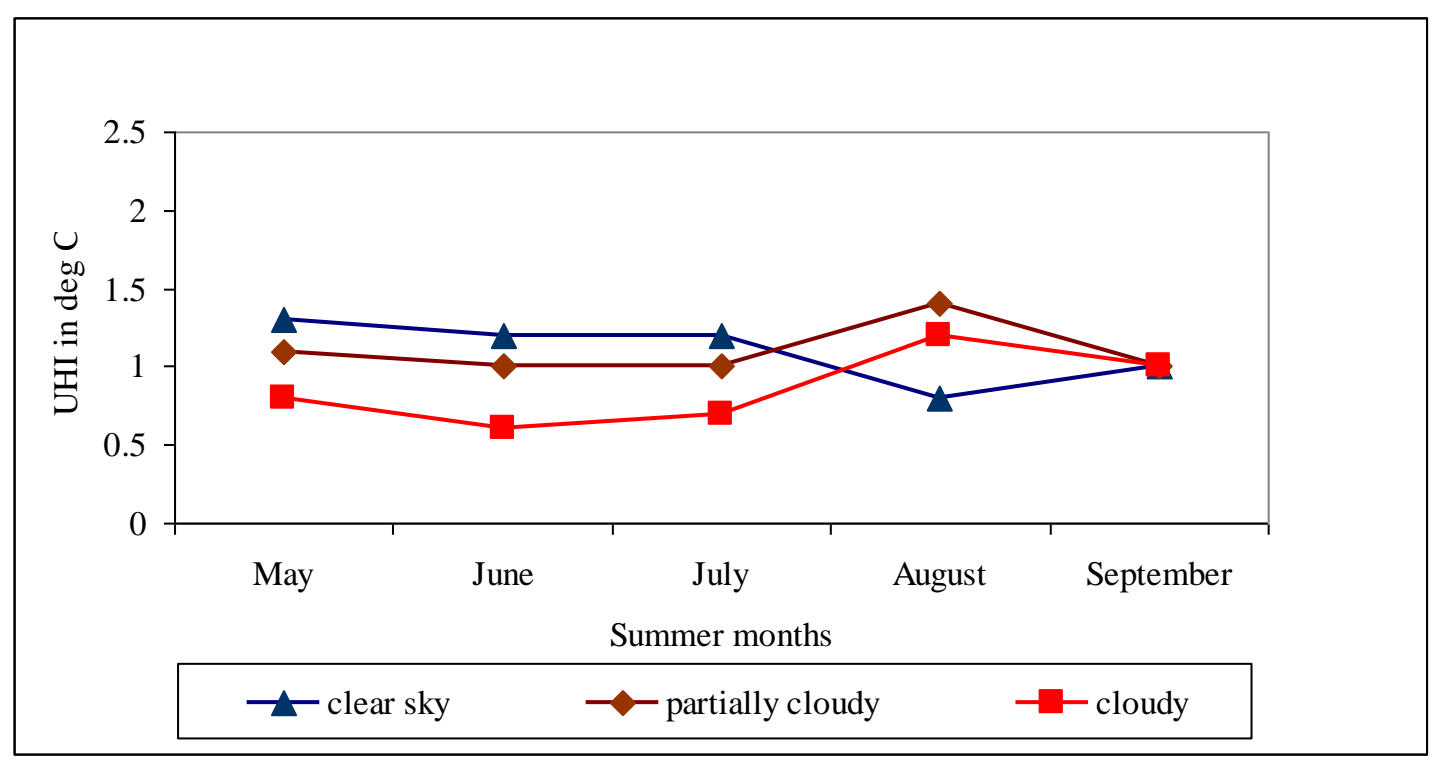

Figure 2a: Mean daytime UHI pattern during summer 2000; wind is not controlled

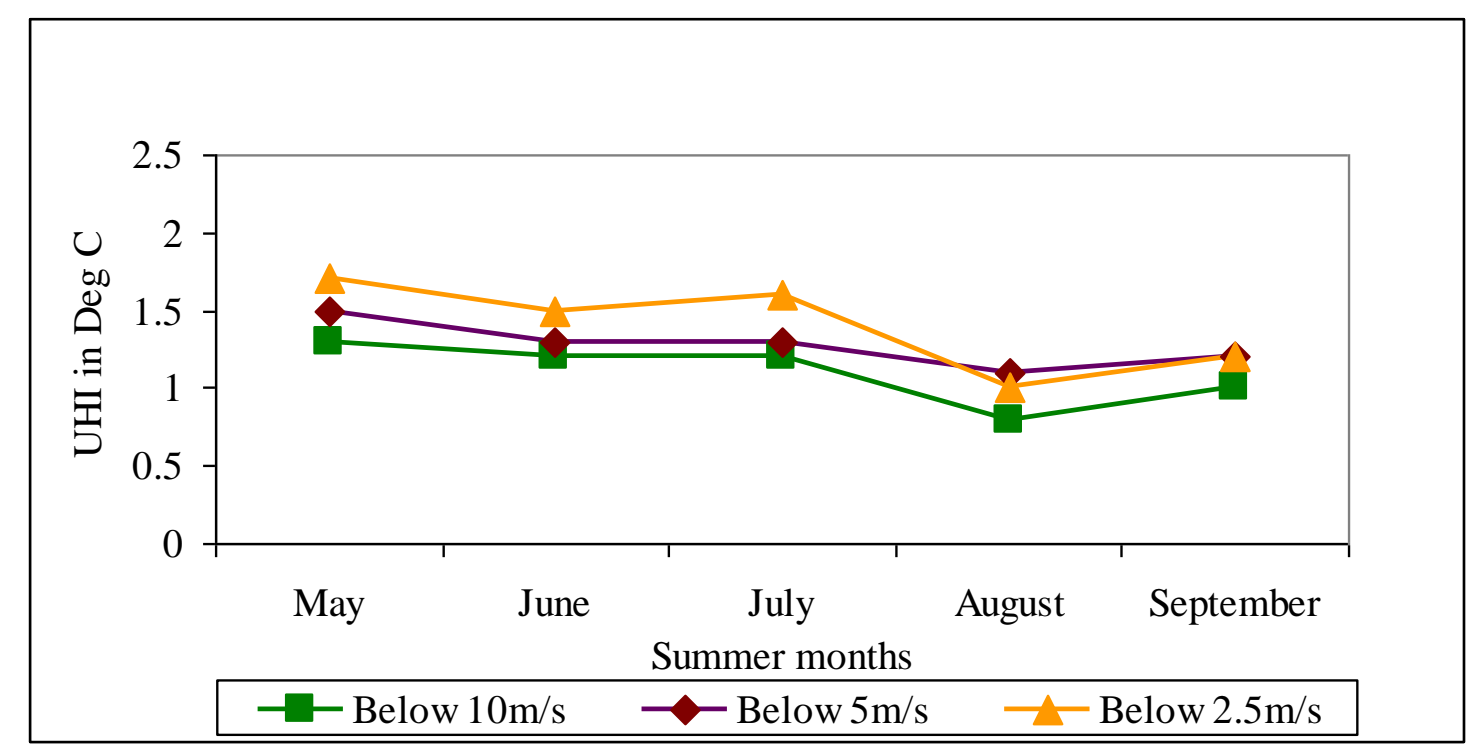

Figure 2b: Mean daytime UHI pattern during clear sky periods under 3 categories of wind velocity 


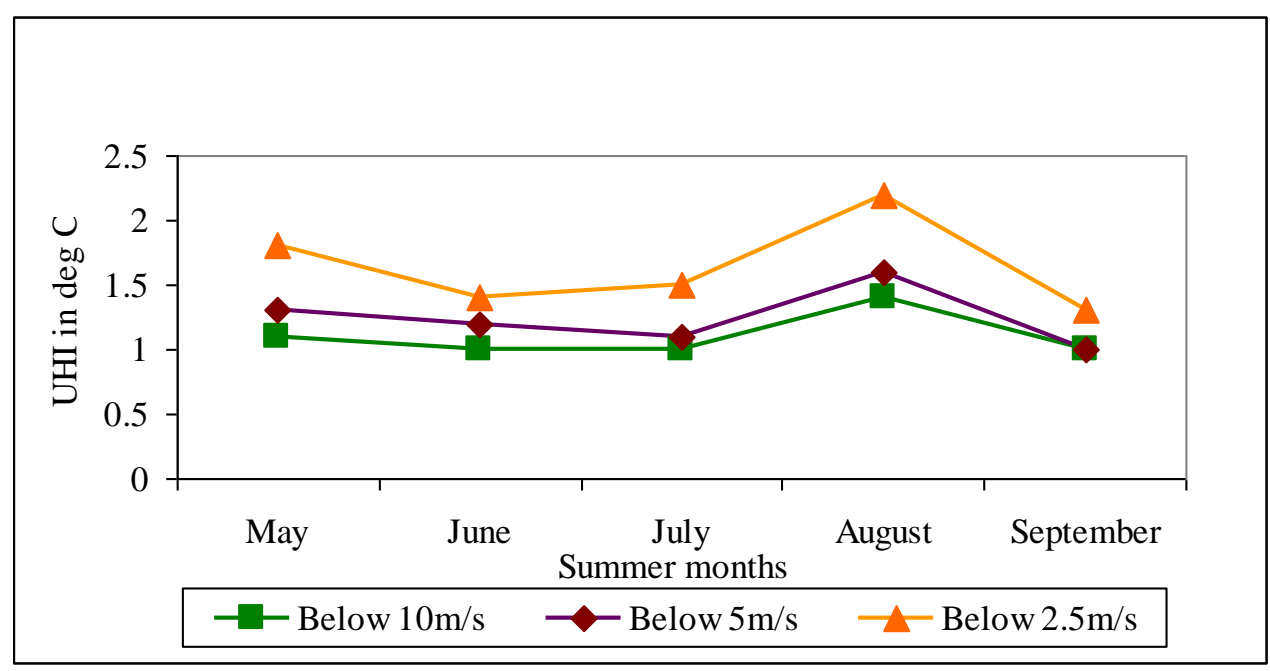

Figure 2c: Mean daytime UHI pattern during partially cloudy periods under 3 categories of wind velocity.

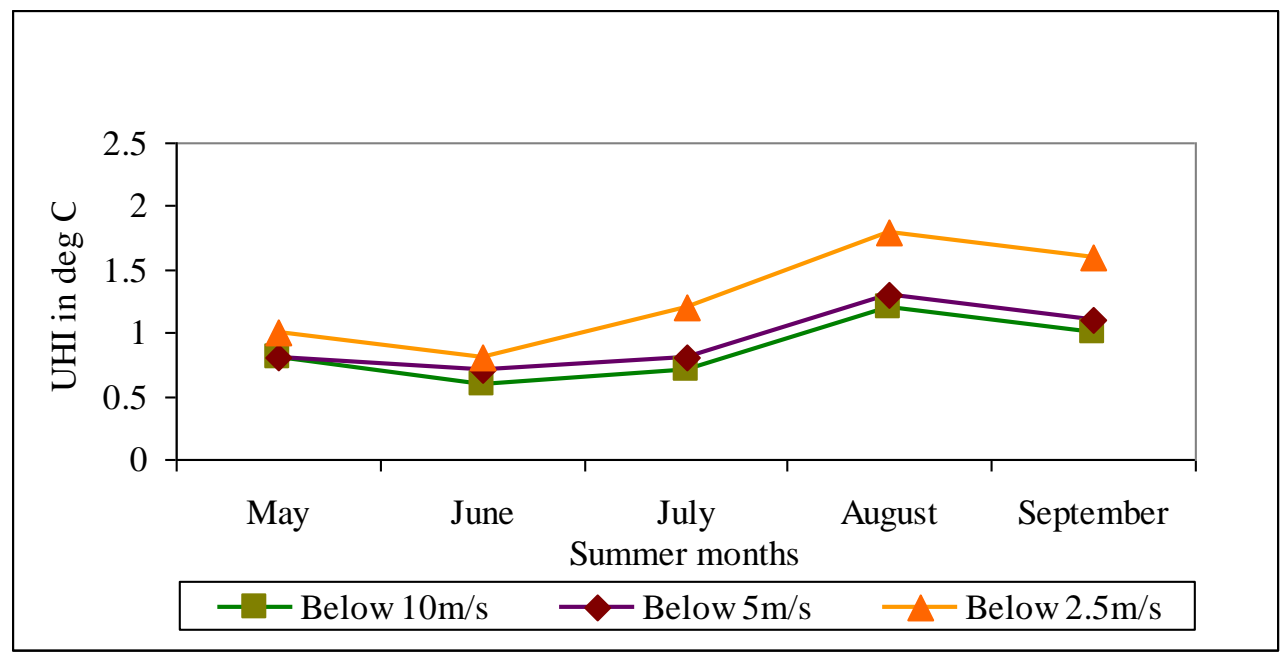

Figure 2d: Mean daytime UHI pattern during cloudy periods under 3 categories of wind velocity. 


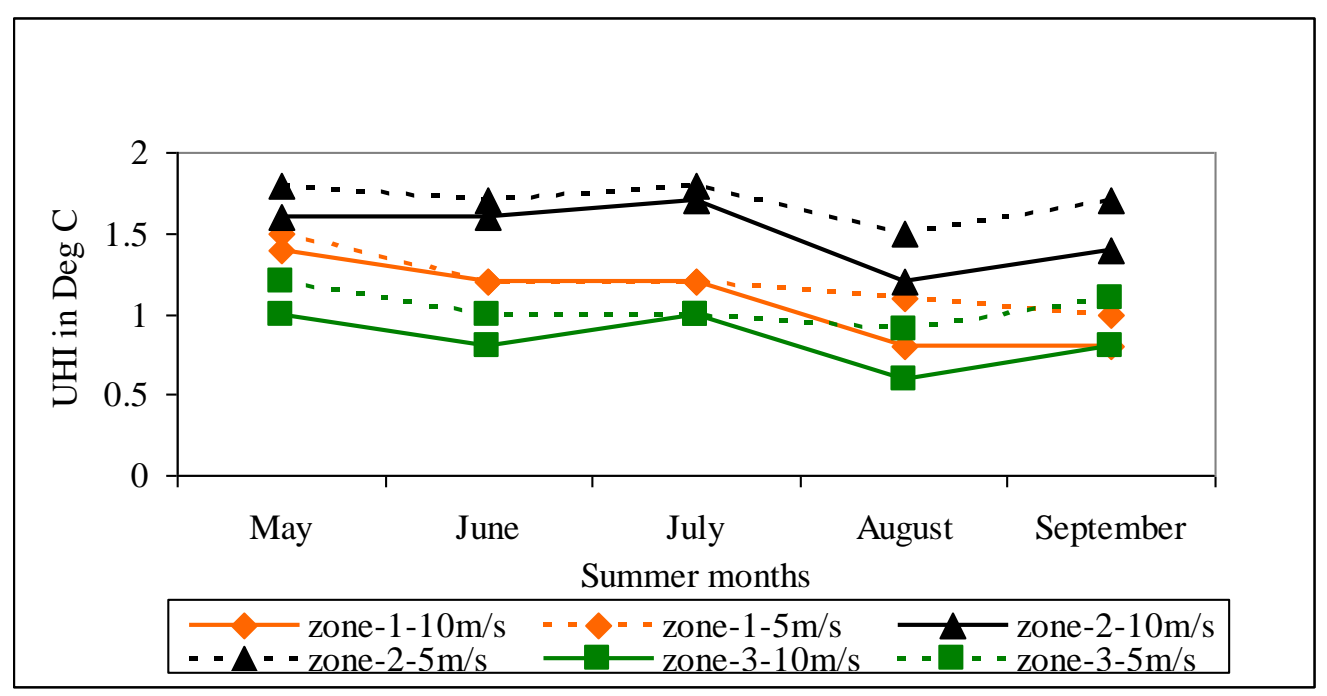

Figure 3a: Mean daytime UHI pattern in 3 geographical zones during clear sky periods under 3 categories of wind velocity.

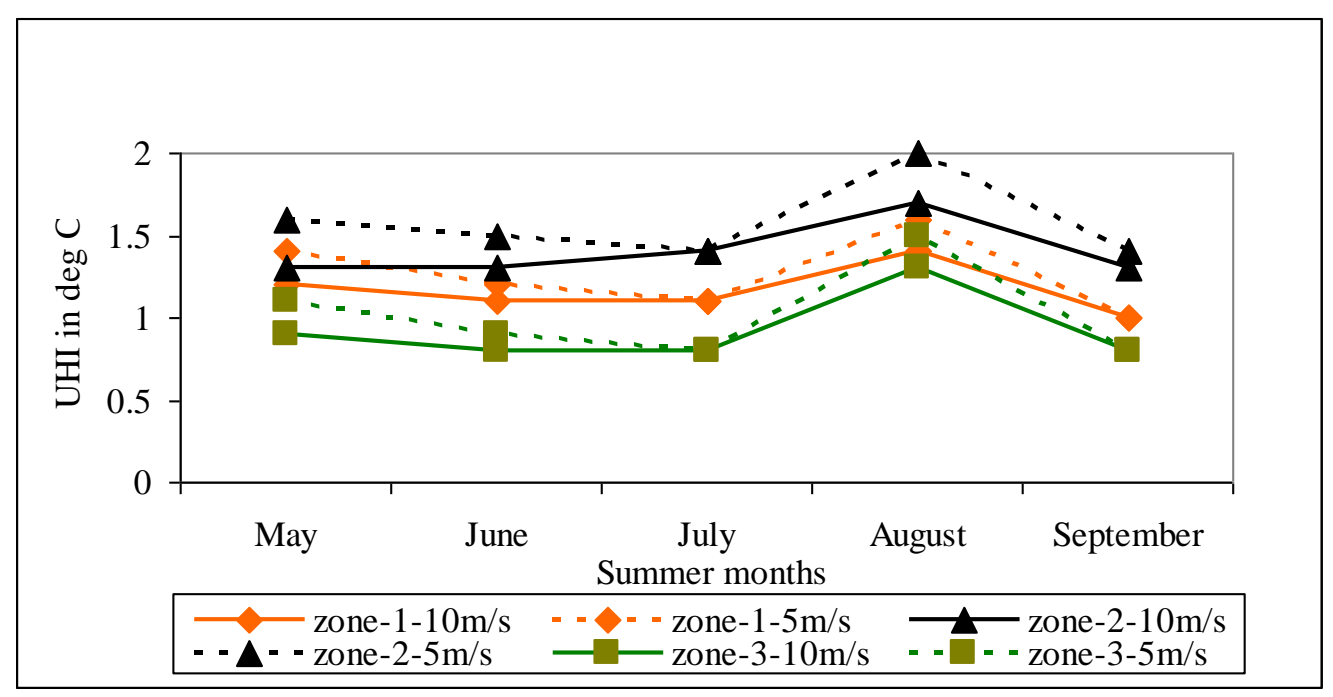

Figure 3b: Mean daytime UHI pattern in 3 geographical zones during partially cloudy periods under 3 categories of wind velocity. 


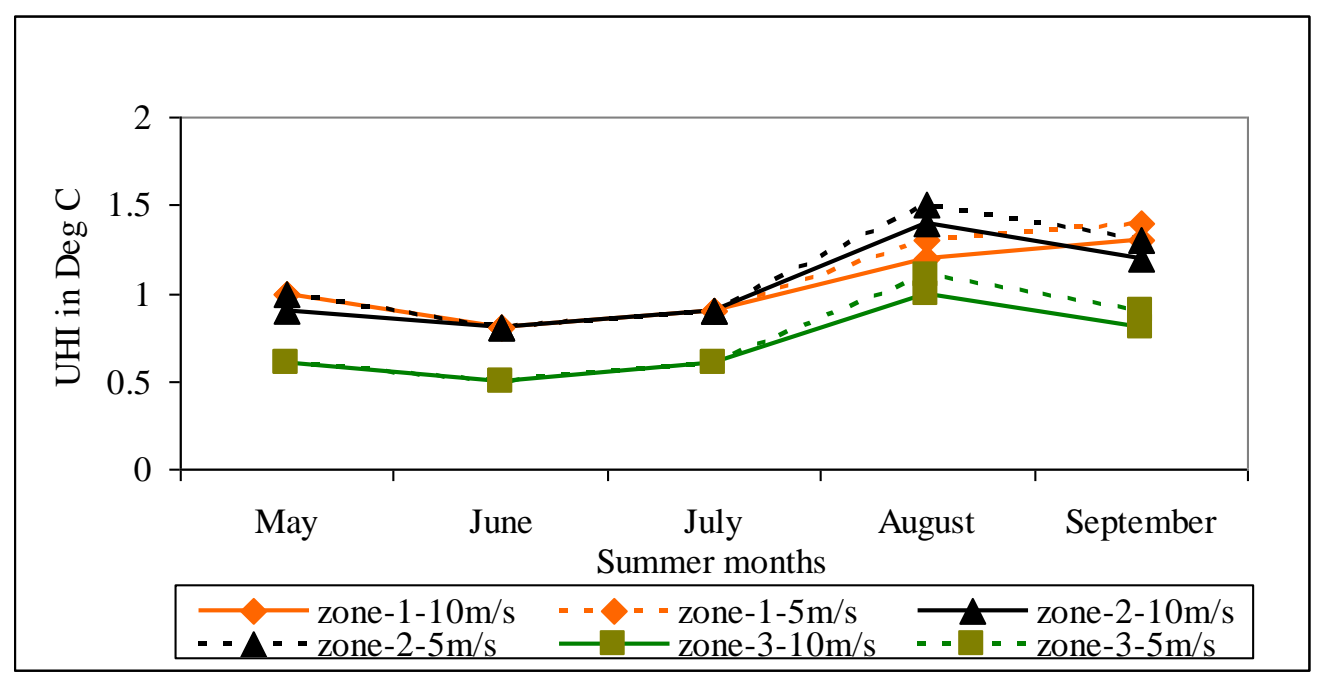

Figure 3c: Mean daytime UHI pattern in 3 geographical zones during cloudy periods under 3 categories of wind velocity. 


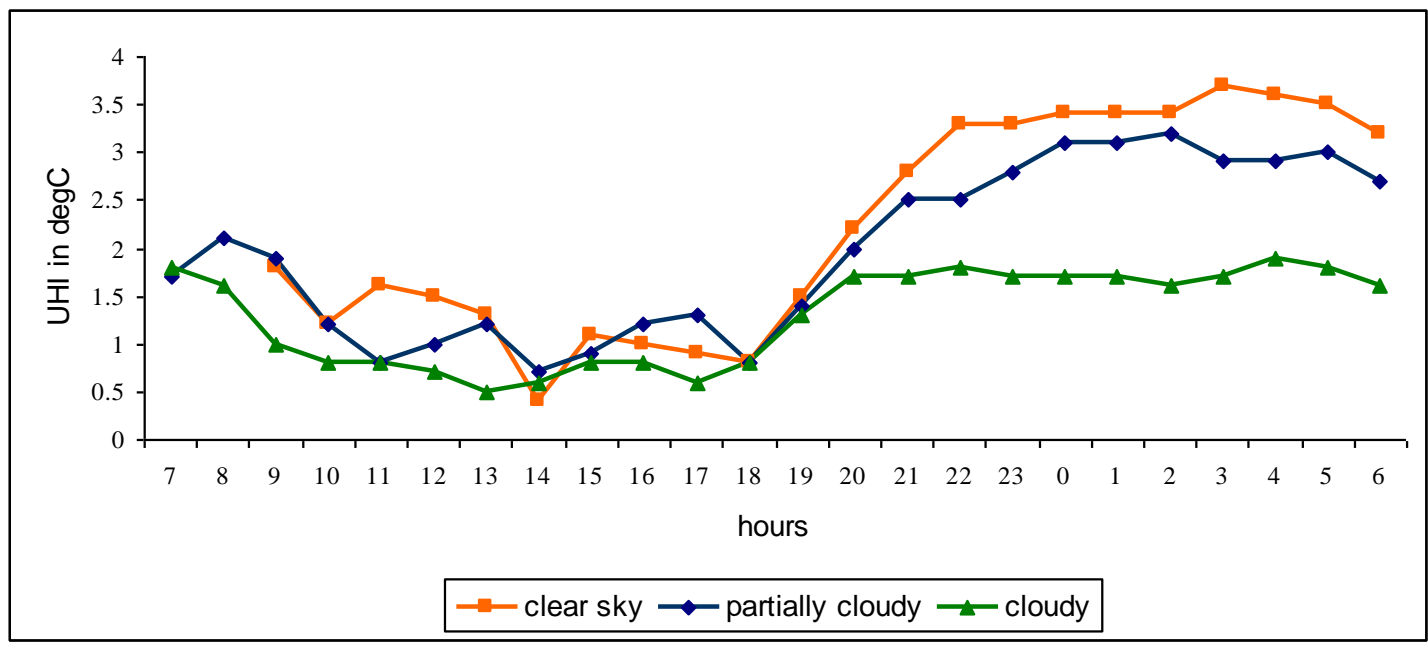

Figure 4a: Hourly mean UHI value with wind velocity less than $5 \mathrm{~m} / \mathrm{s}$ for Core Area (zone-1)

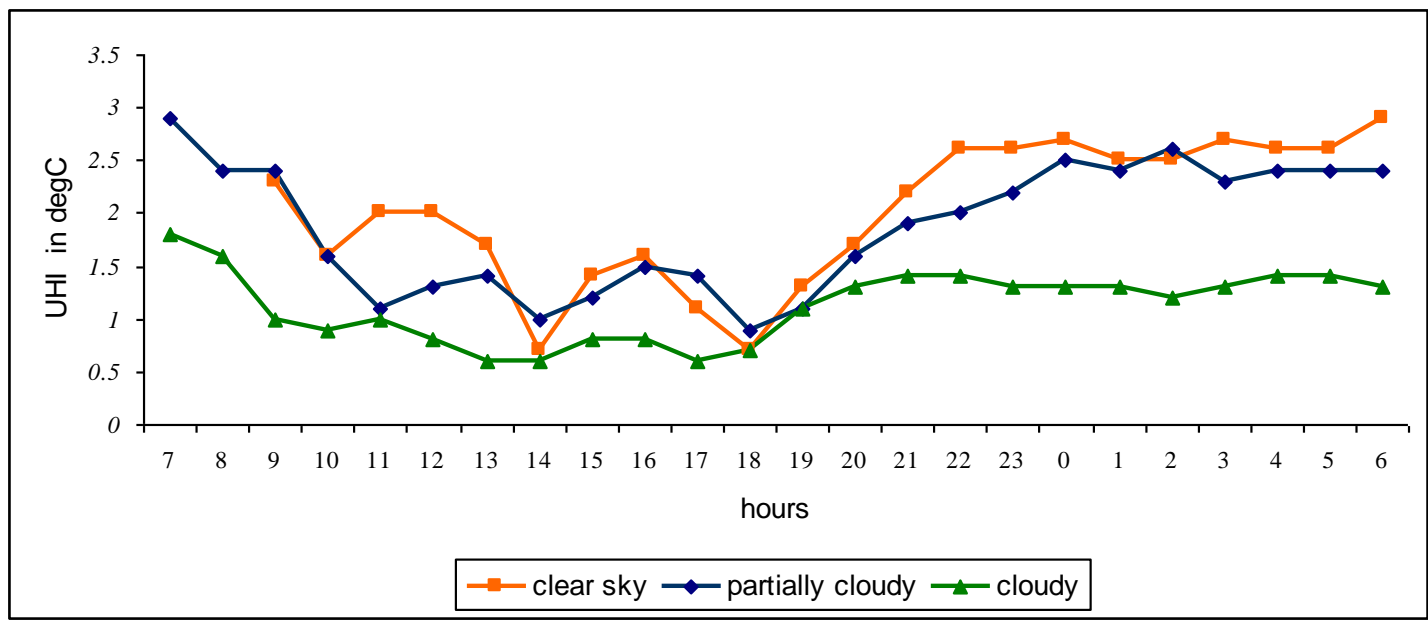

Figure 4b: Hourly mean UHI value with wind velocity less than $5 \mathrm{~m} / \mathrm{s}$ for Urban Area (zone-2) 


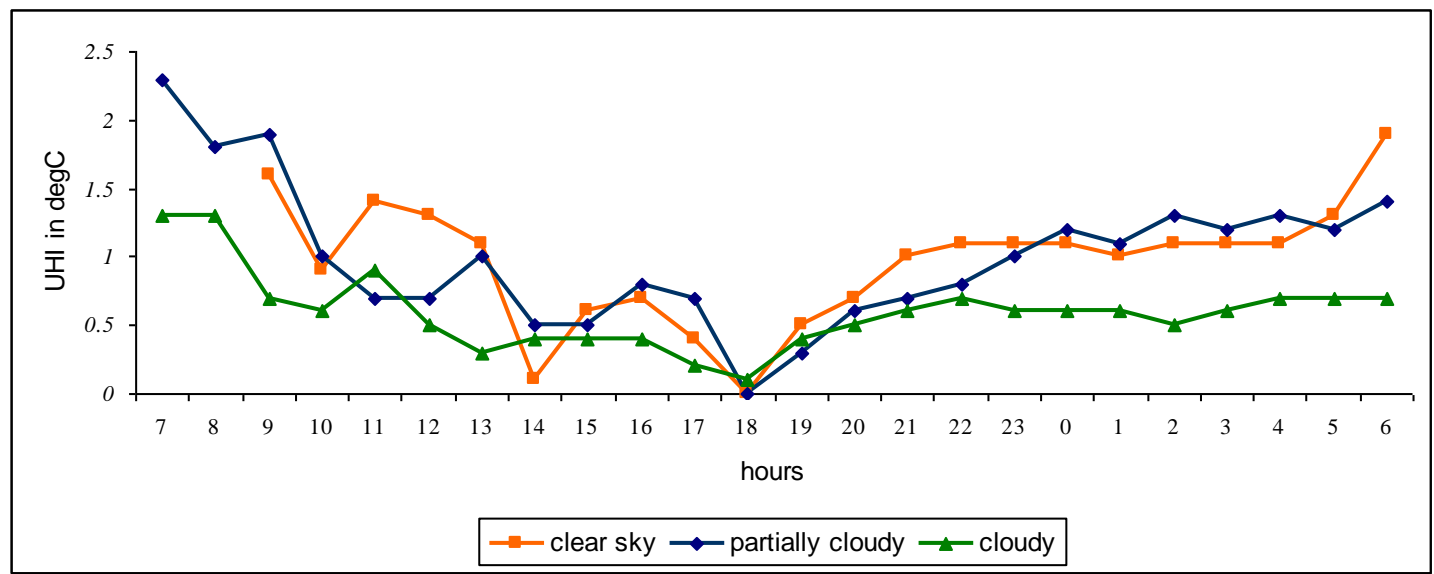

Figure 4c: Hourly mean UHI value with wind velocity less than $5 \mathrm{~m} / \mathrm{s}$ for Semi Urban area (zone-3) 


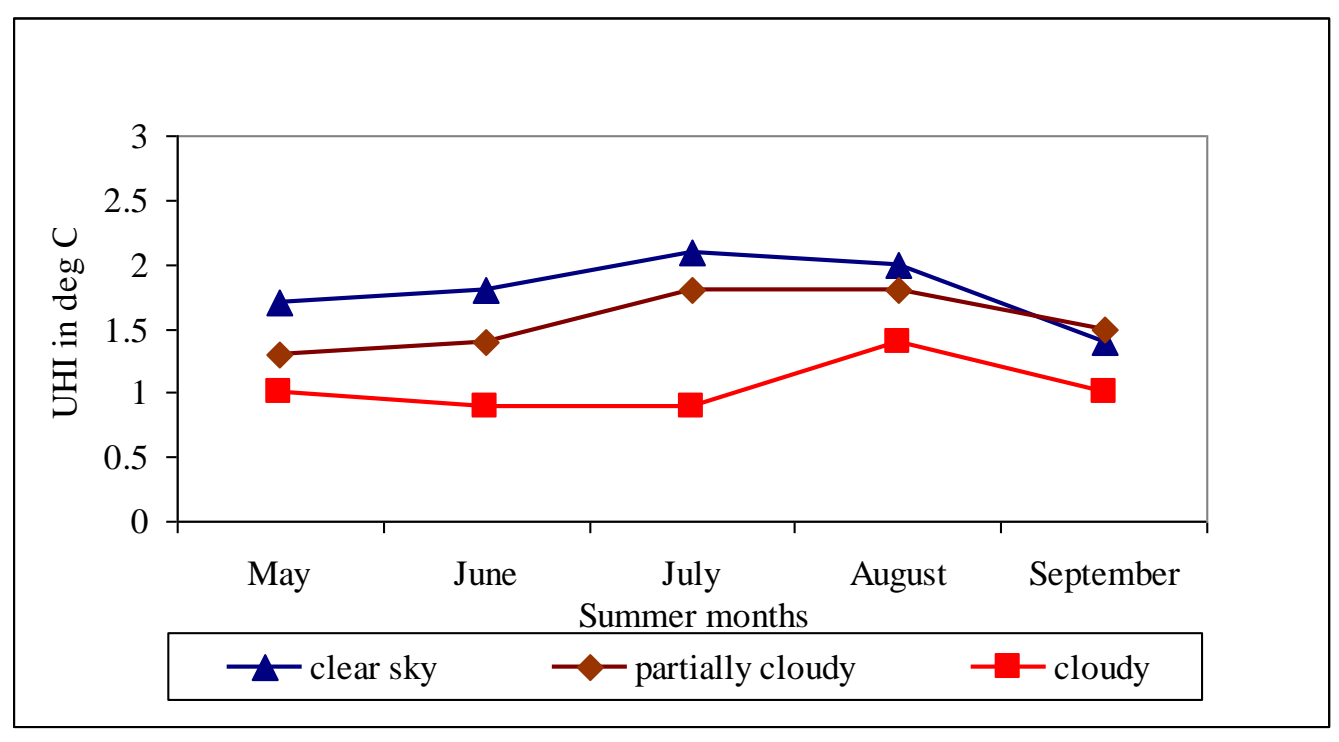

Figure 5a: Mean nocturnal UHI pattern during summer 2000; wind is not controlled

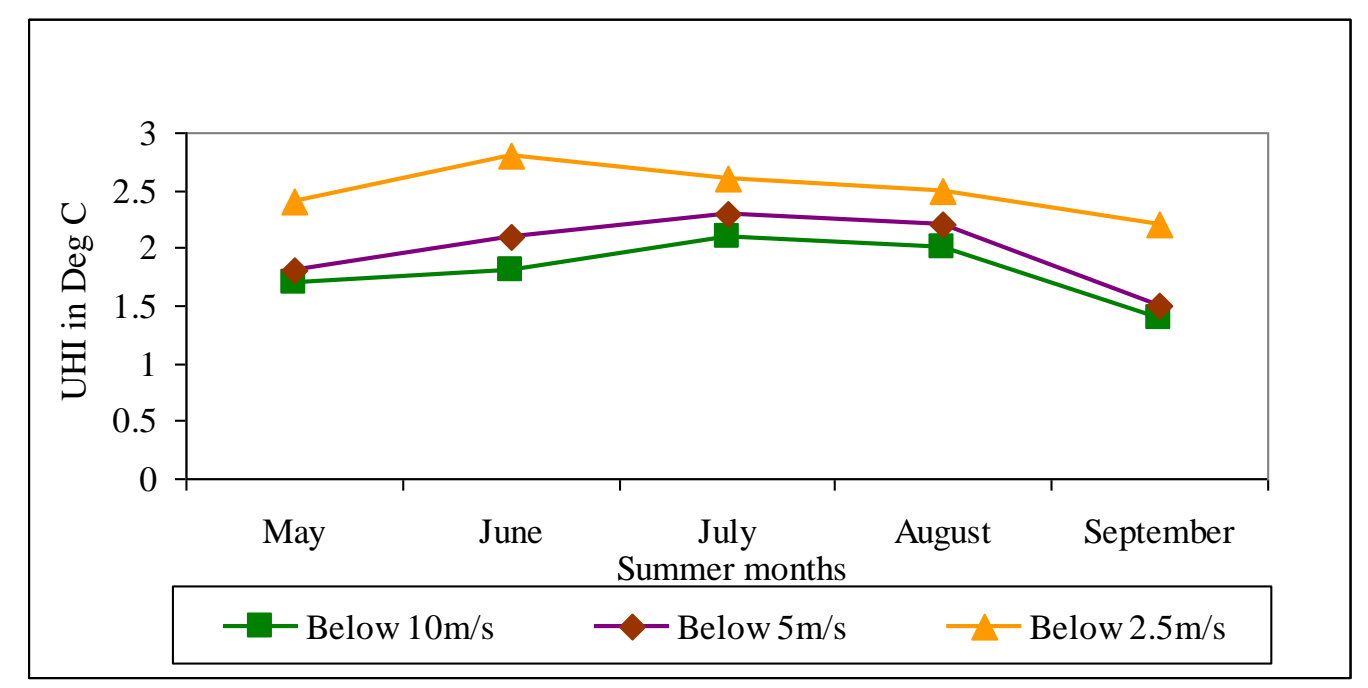

Figure 5b: Mean nocturnal UHI pattern during clear sky periods under 3 categories of wind velocity 


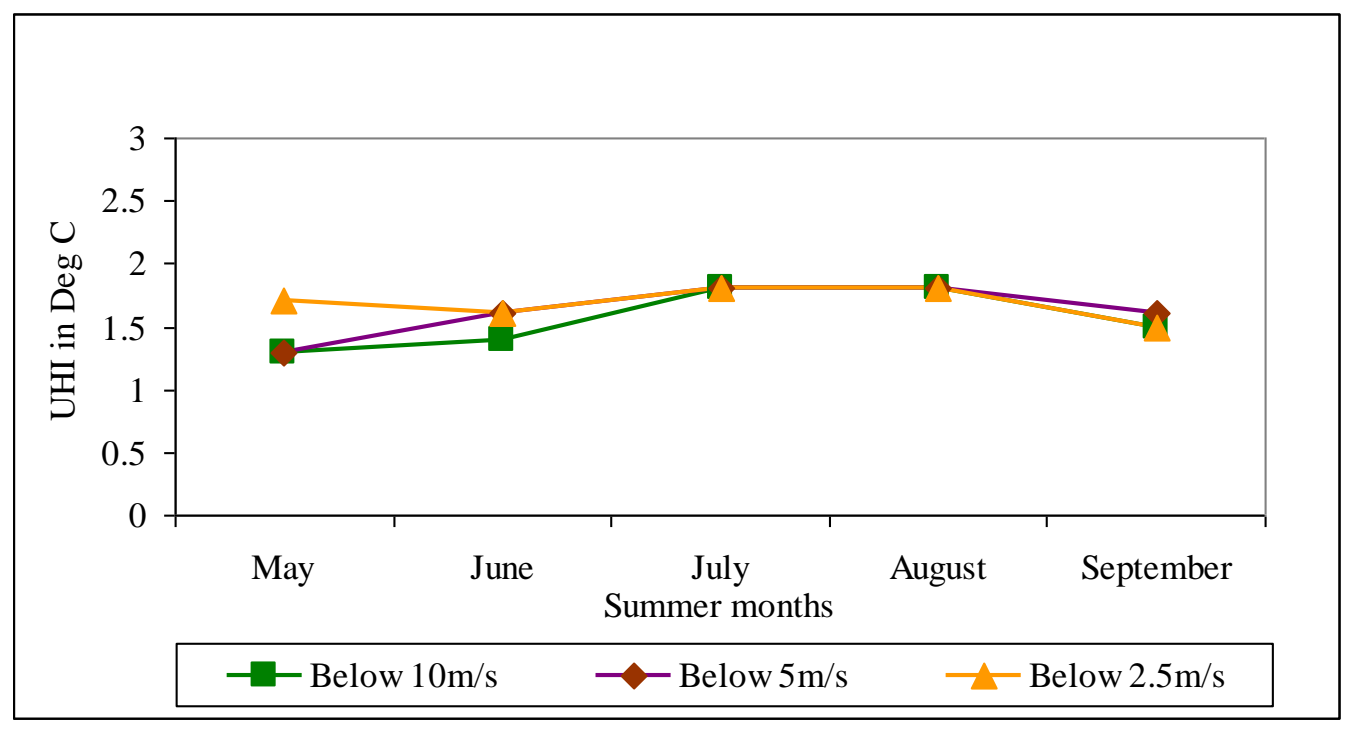

Figure 5c: Mean nocturnal UHI pattern during partially cloudy periods under 3 categories of wind velocity.

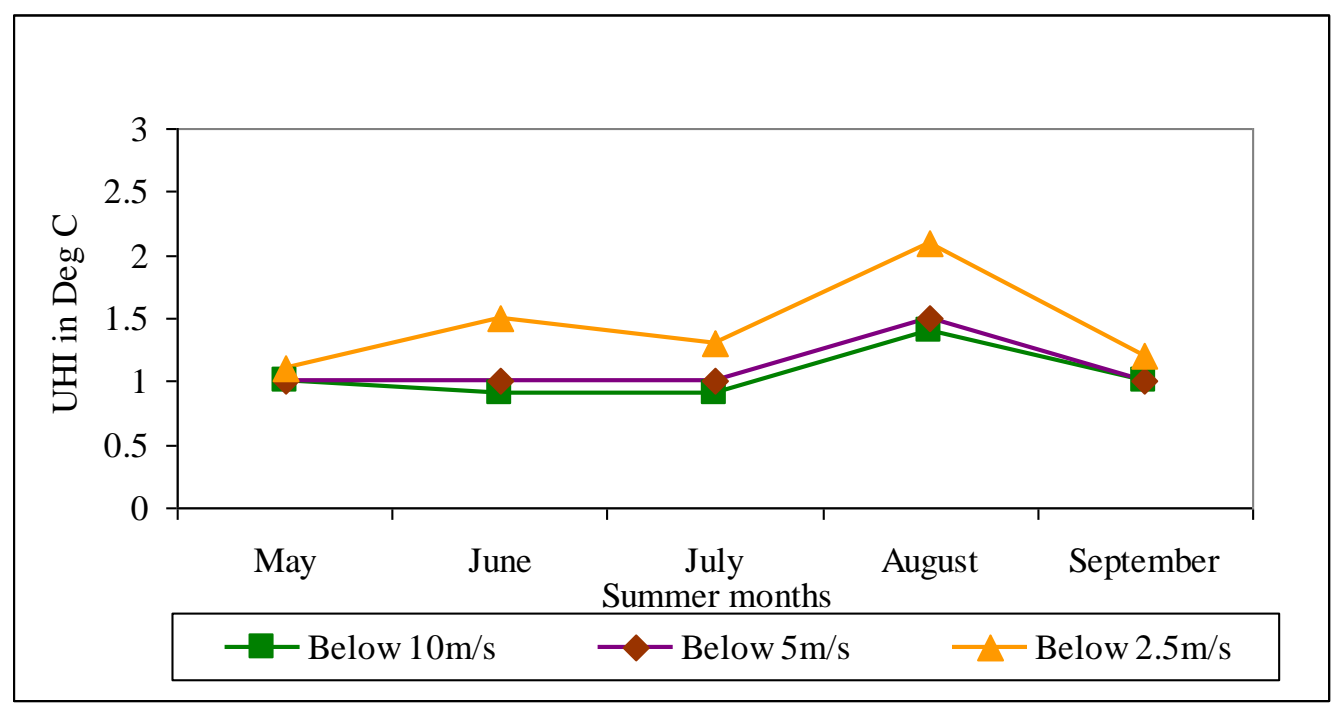

Figure 5d: Mean nocturnal UHI pattern during cloudy periods under 3 categories of wind velocity. 


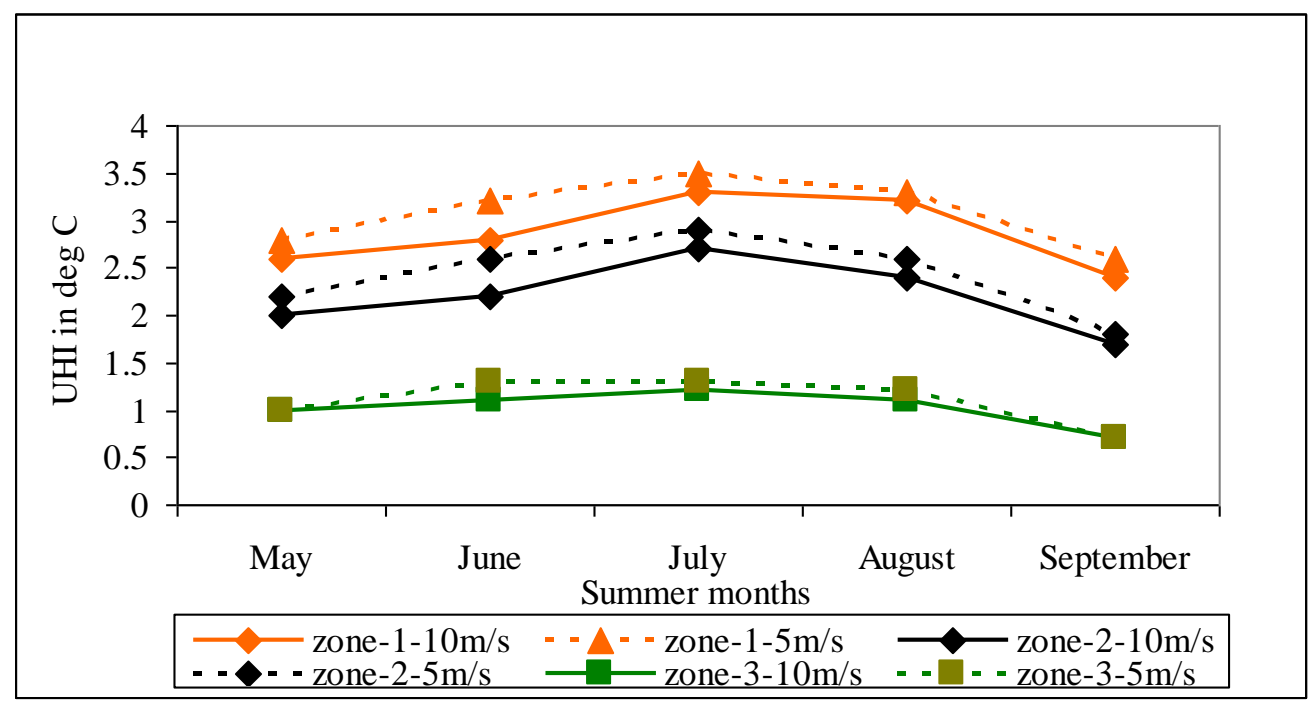

Figure 6a: Mean nocturnal UHI pattern in 3 geographical zones during clear sky periods under 3 categories of wind velocity.

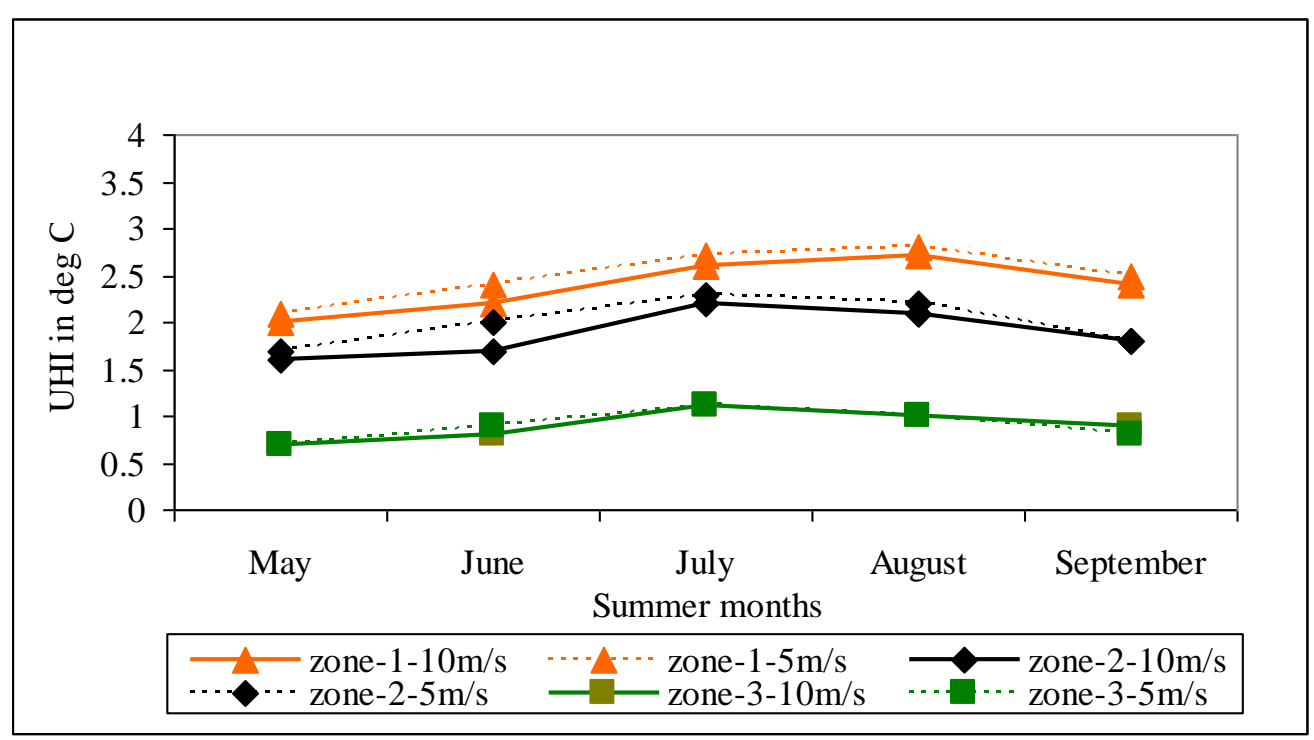

Figure 6b: Mean nocturnal UHI pattern in 3 geographical zones during partially cloudy periods under 3 categories of wind velocity. 


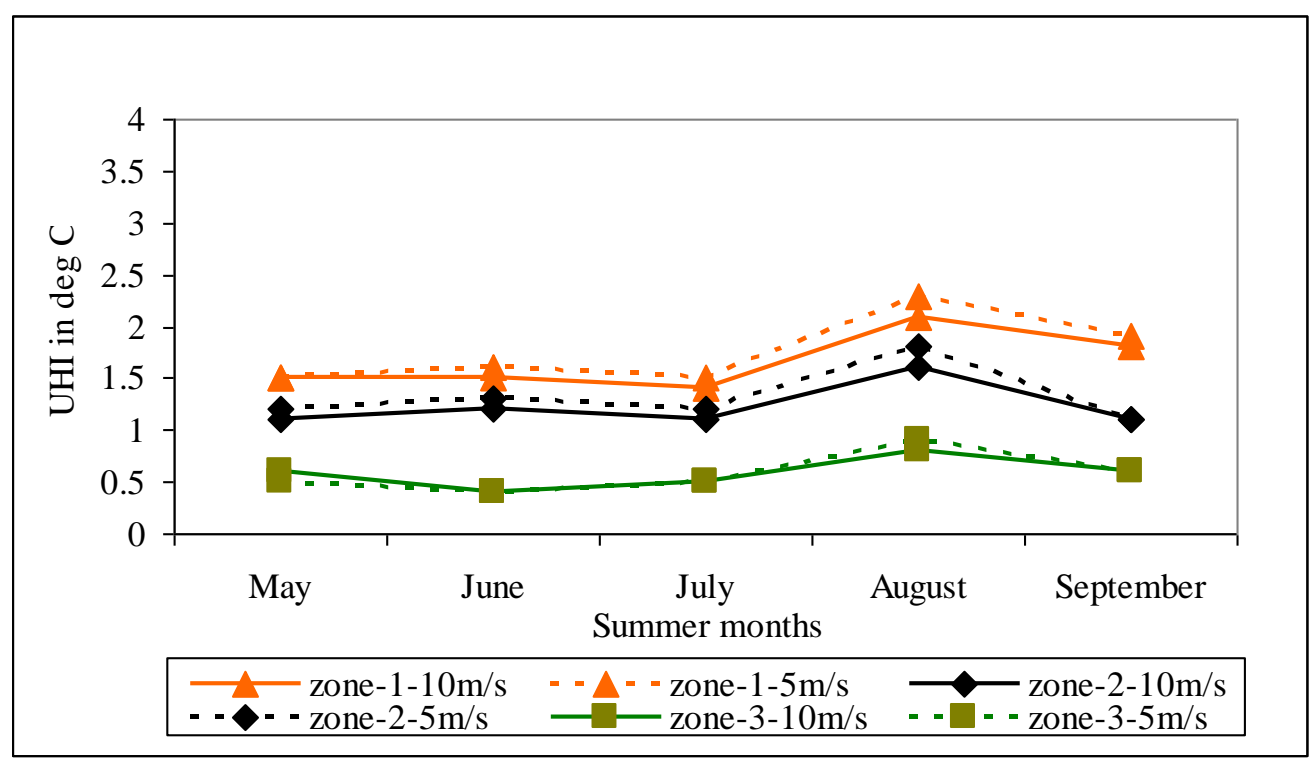

Figure 6c: Mean nocturnal UHI pattern in 3 geographical zones during cloudy periods under 3 categories of wind velocity. 
Table 1: Summer time climate classifications for London

\begin{tabular}{llll}
\hline Description & $\begin{array}{l}\text { Solar radiation } \\
\text { intensity }\left(\mathbf{W} / \mathbf{m}^{2}\right)\end{array}$ & $\begin{array}{l}\text { Cloud Cover } \\
\text { (Oktas) }\end{array}$ & $\begin{array}{l}\text { Wind velocity } \\
(\mathbf{m} / \mathbf{s})\end{array}$ \\
\hline Clear-sky periods & $>500$ & $<4$ & Each of the \\
$(\mathrm{CSP})$ & & category is divided \\
\hline Partially cloudy & 300 to 500 & 4 to 6 & into three wind \\
periods (PCP) & & & spectrums $(10,5$ \\
\hline Cloudy periods & $<300$ & & and 2.5) \\
(CP) & & & \\
\hline
\end{tabular}

Note: The hourly solar radiation intensity and cloud cover data are from London Weather Station while the wind velocity is from Heathrow Weather Station. 
Table 2: General climatic characteristic of London during the study period.

\begin{tabular}{|c|c|c|c|c|c|c|c|c|}
\hline \multirow[t]{2}{*}{$\begin{array}{l}\text { Descript } \\
\text { ion }\end{array}$} & \multirow[t]{2}{*}{$\begin{array}{c}\text { Peri } \\
\text { od }\end{array}$} & \multicolumn{2}{|c|}{$\begin{array}{l}\text { London } \\
\text { weather } \\
\text { station }\end{array}$} & \multicolumn{4}{|c|}{ Heathrow weather station } & \multirow{2}{*}{\begin{tabular}{l}
$\begin{array}{l}\text { Referen } \\
\text { ce } \\
\text { station }\end{array}$ \\
\multicolumn{1}{c}{ Air } \\
temperat \\
ure $\left({ }^{\circ} \mathrm{C}\right)$
\end{tabular}} \\
\hline & & $\begin{array}{c}\text { Solar } \\
\text { radiati } \\
\text { on } \\
\text { intensi } \\
\text { ty } \\
\left(\mathrm{W} / \mathrm{m}^{2}\right. \\
)\end{array}$ & $\begin{array}{c}\text { Clou } \\
\text { d } \\
\text { cover } \\
\text { (Okta } \\
\text { s) }\end{array}$ & $\begin{array}{c}\text { Air } \\
\text { temperat } \\
\text { ure } \\
\left({ }^{\circ} \mathrm{C}\right)\end{array}$ & $\begin{array}{l}\text { Wind } \\
\text { veloci } \\
\text { ty } \\
(\mathrm{m} / \mathrm{s})\end{array}$ & $\begin{array}{l}\text { Precipitat } \\
\text { ion }(\mathrm{mm})\end{array}$ & $\begin{array}{l}\text { Relati } \\
\text { ve } \\
\text { humid } \\
\text { ity } \\
(\%)\end{array}$ & \\
\hline $\begin{array}{l}\text { Clear } \\
\text { sky } \\
\text { period } \\
(\mathrm{CSP})\end{array}$ & $\begin{array}{c}\text { Day } \\
\text { Nigh } \\
t\end{array}$ & $\begin{array}{l}645.3 \\
27.4\end{array}$ & $\begin{array}{l}4 \\
2\end{array}$ & $\begin{array}{l}20.5 \\
15.1\end{array}$ & $\begin{array}{l}3.9 \\
2.3\end{array}$ & $\begin{array}{l}1.2 \\
6.8\end{array}$ & $\begin{array}{l}51.2 \\
76.7\end{array}$ & $\begin{array}{l}20.7 \\
13.4\end{array}$ \\
\hline $\begin{array}{l}\text { Partially } \\
\text { Cloudy } \\
\text { period } \\
(\mathrm{PCP})\end{array}$ & $\begin{array}{c}\text { Day } \\
\text { Nigh } \\
\mathrm{t}\end{array}$ & $\begin{array}{c}390.6 \\
26.9\end{array}$ & $\begin{array}{l}6 \\
5\end{array}$ & $\begin{array}{l}18.3 \\
15.1\end{array}$ & $\begin{array}{l}3.8 \\
2.5\end{array}$ & $\begin{array}{c}25.8 \\
2.8\end{array}$ & $\begin{array}{l}61.6 \\
77.0\end{array}$ & $\begin{array}{l}17.8 \\
13.7\end{array}$ \\
\hline $\begin{array}{l}\text { Cloudy } \\
\text { period } \\
\text { (CP) }\end{array}$ & $\begin{array}{c}\text { Day } \\
\text { Nigh } \\
t\end{array}$ & $\begin{array}{c}161.3 \\
13.5\end{array}$ & $\begin{array}{l}7 \\
7\end{array}$ & $\begin{array}{l}16.3 \\
14.5\end{array}$ & $\begin{array}{l}3.4 \\
2.8\end{array}$ & $\begin{array}{l}144.2 \\
111.4\end{array}$ & $\begin{array}{l}74.4 \\
82.4\end{array}$ & $\begin{array}{l}15.7 \\
13.4\end{array}$ \\
\hline
\end{tabular}

Note: 1. Mean values for May to September are presented except precipitation which is cumulative for the period. 
Table 3: Geographical classification of London

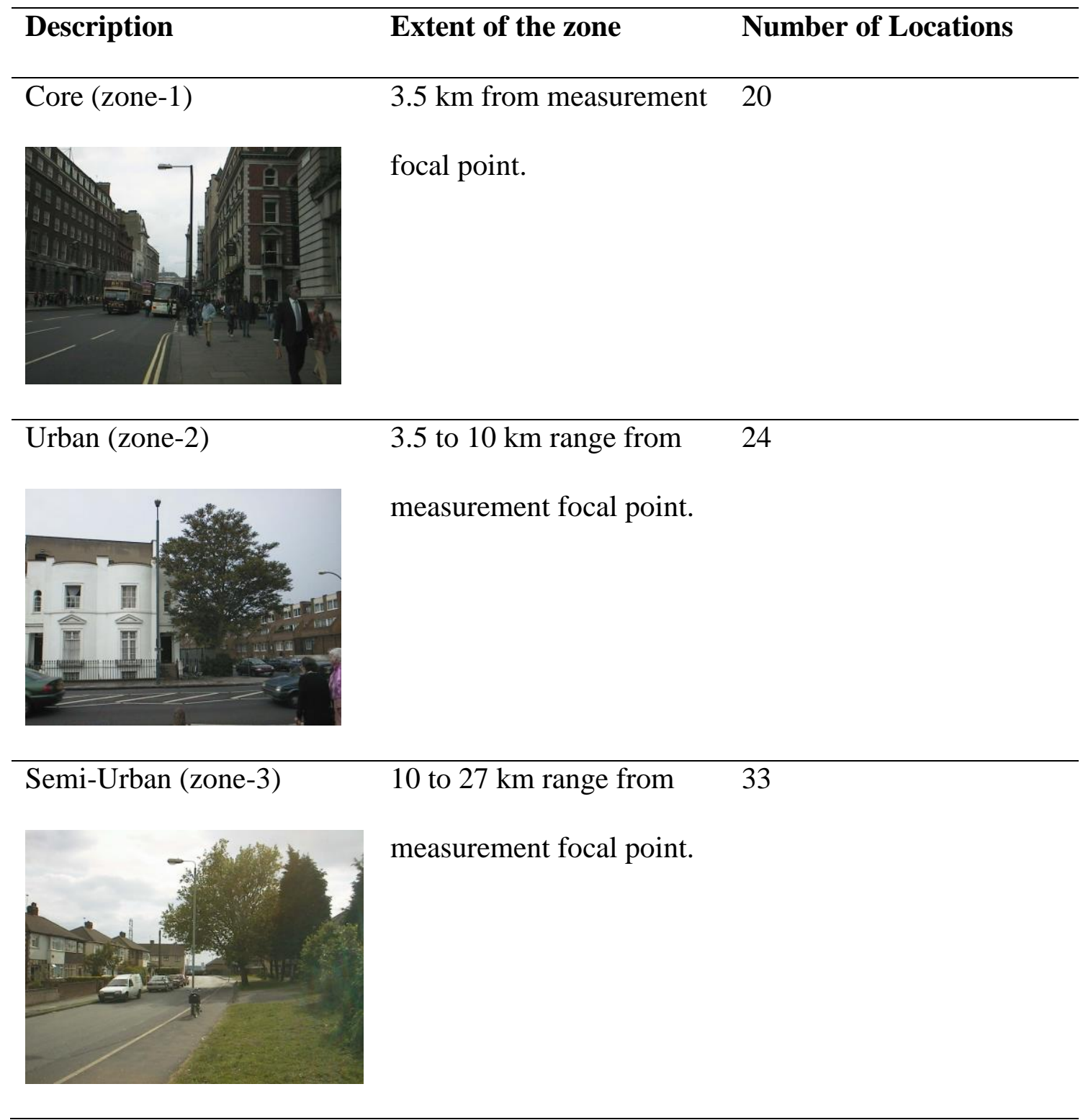

Note: The study considers British museum as focal point of London because this is the central point of the measurements network. In reality the thermal centre might be slightly different but this shifts during the day, season and weather conditions. Therefore, a convenient geographical centre in central London has been used as the focal point throughout the study (Watkins, 2002) 
Table 4: Data range of the independent variables

\begin{tabular}{|c|c|c|c|c|c|}
\hline $\begin{array}{l}\text { Independent } \\
\text { variable }\end{array}$ & Definition & $\begin{array}{l}\text { Minimum } \\
\text { value in the } \\
\text { data }\end{array}$ & $\begin{array}{l}\text { Average } \\
\text { value in } \\
\text { the data } \\
\text { set }\end{array}$ & $\begin{array}{l}\text { Maximum } \\
\text { value in } \\
\text { the data } \\
\text { set }\end{array}$ & $\begin{array}{l}\text { Accepted } \\
\text { sign for } \\
\text { regression } \\
\text { coefficient } \\
\text { day/night }\end{array}$ \\
\hline Aspect Ratio & $\begin{array}{l}\text { Height to width } \\
\text { ratio }\end{array}$ & 0 & 0.4 & 3.2 & $-/+$ \\
\hline Plan density ratio & $\begin{array}{l}\text { Foot print area } \\
\text { to } \\
\text { environmental } \\
\text { area ratio }\end{array}$ & 0 & 0.3 & 0.8 & $+/+$ \\
\hline Fabric density ratio & $\begin{array}{l}\text { Vertical surface } \\
\text { area to } \\
\text { environmental } \\
\text { area ratio }\end{array}$ & 0 & 0.3 & 1.2 & $+/+$ \\
\hline Green density ratio & $\begin{array}{l}\text { Green area to } \\
\text { environmental } \\
\text { area ratio }\end{array}$ & 0 & 0.4 & 1 & $-/-$ \\
\hline $\begin{array}{l}\text { Thermal mass } \\
(\mathrm{J} / \mathrm{kgK})\end{array}$ & $\begin{array}{l}\text { Specific heat } \\
\text { capacity }\end{array}$ & 830 & 951.8 & 1380 & $-/+$ \\
\hline Surface albedo & $\begin{array}{l}\text { Outgoing to } \\
\text { incoming } \\
\text { radiation ratio }\end{array}$ & 0.13 & 0.2 & 0.48 & $-/-$ \\
\hline
\end{tabular}


Table 5: Maximum daytime UHI $\left({ }^{\circ} \mathrm{C}\right)$ in 3 geographical zones during the 3 climate variations when the wind velocity is below $5 \mathrm{~m} / \mathrm{s}$.

\begin{tabular}{llll}
\hline Description & Core (zone-1) & Urban (zone-2) & Semi-urban (zone-3) \\
\hline Clear sky Period (CSP) & 6.1 & 6.9 & 7.4 \\
\hline Partially cloudy period (PCP) & 7.2 & 8.0 & 8.9 \\
\hline Cloudy period (CP) & 7.9 & 8.4 & 8.8 \\
\hline
\end{tabular}


Table 6: Maximum nocturnal UHI $\left({ }^{\circ} \mathrm{C}\right)$ in 3 geographical zones during the 3 climate variations when the wind velocity is below $5 \mathrm{~m} / \mathrm{s}$.

\begin{tabular}{llll}
\hline Description & Core (zone-1) & Urban (zone-2) & Semi-urban (zone-3) \\
\hline Clear sky period (CSP) & 7.6 & 8.6 & 7.5 \\
\hline Partially cloudy period (PCP) & 7.3 & 7.0 & 6.4 \\
\hline Cloudy period (CP) & 6.6 & 6.3 & 5.8 \\
\hline
\end{tabular}


Table 7: Regression results of 6 variables daytime climate models.

\begin{tabular}{|c|c|c|c|c|c|c|c|c|c|}
\hline \multirow{3}{*}{$\begin{array}{l}\text { Description } \\
\text { Variables }\end{array}$} & \multicolumn{3}{|c|}{ Clear sky periods } & \multicolumn{3}{|c|}{ Partially cloudy periods } & \multicolumn{3}{|c|}{ Cloudy periods } \\
\hline & \multicolumn{2}{|c|}{ Coefficient } & \multirow{2}{*}{$\begin{array}{r}\text { Significant } \\
\text { level }\end{array}$} & \multicolumn{2}{|c|}{ Coefficient } & \multirow{2}{*}{$\begin{array}{r}\text { Significant } \\
\text { level }\end{array}$} & \multicolumn{2}{|c|}{ Coefficient } & \multirow{2}{*}{$\begin{array}{r}\text { Significant } \\
\text { level }\end{array}$} \\
\hline & $\mathrm{B}$ & Beta & & $\mathrm{B}$ & Beta & & $\mathrm{B}$ & Beta & \\
\hline Surface albedo (SA) & -2.20 & -0.24 & 0.176 & -2.32 & -0.30 & 0.066 & -1.82 & -0.30 & 0.047 \\
\hline Aspect ratio (AR) & -0.19 & -0.17 & 0.235 & -0.23 & -0.23 & 0.061 & -0.17 & -0.22 & 0.054 \\
\hline Thermal mass (TM) & -0.001 & -0.19 & 0.208 & $-1.0 \mathrm{E}-03$ & -0.20 & 0.140 & $-6.4 \mathrm{E}-07$ & $-1.9 \mathrm{E}-04$ & 0.999 \\
\hline Green density ratio (GDR) & -0.54 & -0.24 & 0.279 & -0.72 & -0.38 & 0.062 & -0.35 & -0.23 & 0.214 \\
\hline Plan density ratio (PDR) & 0.24 & 0.08 & 0.780 & 0.29 & 0.11 & 0.668 & 0.17 & 0.08 & 0.729 \\
\hline Fabric density ratio (FDR) & 0.35 & 0.15 & 0.549 & 0.10 & 0.05 & 0.817 & 0.38 & 0.25 & 0.240 \\
\hline Constant & 2.80 & & & 2.91 & & & 1.43 & & \\
\hline $\mathbf{R}^{2}$ & \multicolumn{3}{|c|}{0.23} & \multicolumn{3}{|c|}{0.36} & \multicolumn{3}{|c|}{0.45} \\
\hline F static & \multicolumn{3}{|c|}{3.54} & \multicolumn{3}{|c|}{6.49} & \multicolumn{3}{|c|}{9.42} \\
\hline Critical ' $\mathrm{F}$ ' static & \multicolumn{3}{|c|}{2.34} & \multicolumn{3}{|c|}{2.34} & \multicolumn{3}{|c|}{2.34} \\
\hline Number of stations & \multicolumn{3}{|c|}{76} & \multicolumn{3}{|c|}{76} & \multicolumn{3}{|c|}{76} \\
\hline
\end{tabular}

$\mathrm{B}=$ Unstandardized coefficient.

Beta=Standardized coefficient. 
Table 8: Regression results of 6 variables daytime models of 3 zones during partially cloudy day.

\begin{tabular}{|c|c|c|c|c|c|c|c|c|c|}
\hline \multirow{3}{*}{$\begin{array}{l}\text { Description } \\
\text { Variables }\end{array}$} & \multicolumn{3}{|c|}{ Core area (zone-1) } & \multicolumn{3}{|c|}{ Urban area (zone-2) } & \multicolumn{3}{|c|}{ Semi-Urban area (zone-3) } \\
\hline & \multicolumn{2}{|c|}{ Coefficient } & \multirow[t]{2}{*}{ Significant level } & \multicolumn{2}{|c|}{ Coefficient } & \multirow[t]{2}{*}{ Significant level } & \multicolumn{2}{|c|}{ Coefficient } & \multirow[t]{2}{*}{ Significant level } \\
\hline & $\mathrm{B}$ & Beta & & $\mathrm{B}$ & Beta & & $\mathrm{B}$ & Beta & \\
\hline Surface albedo (SA) & 1.54 & 0.13 & 0.712 & 2.50 & 0.19 & 0.395 & -5.28 & -0.68 & 0.005 \\
\hline Aspect ratio (AR) & -0.07 & -0.11 & 0.762 & -0.20 & -0.29 & 0.226 & 1.16 & 0.21 & 0.289 \\
\hline Thermal mass (TM) & $-6.2 \mathrm{E}-05$ & -0.03 & 0.947 & $1.0 \mathrm{E}-03$ & 0.24 & 0.382 & $1.7 \mathrm{E}-04$ & 0.02 & 0.935 \\
\hline Green density ratio (GDR) & -0.05 & -0.02 & 0.947 & -0.62 & -0.28 & 0.357 & -0.280 & -0.13 & 0.743 \\
\hline Plan density ratio (PDR) & -0.44 & -0.23 & 0.723 & 1.76 & 0.70 & 0.146 & -2.73 & -0.65 & 0.289 \\
\hline Fabric density ratio (FDR) & 0.31 & 0.25 & 0.561 & -0.92 & -0.49 & 0.298 & 1.72 & 0.40 & 0.517 \\
\hline Constant & 1.17 & & & -0.13 & & & 2.54 & & \\
\hline $\mathbf{R}^{2}$ & \multicolumn{3}{|c|}{0.10} & \multicolumn{3}{|c|}{0.39} & \multicolumn{3}{|c|}{0.56} \\
\hline F static & \multicolumn{3}{|c|}{0.22} & \multicolumn{3}{|c|}{1.7} & \multicolumn{3}{|c|}{5.48} \\
\hline Critical 'F' static & \multicolumn{3}{|c|}{2.95} & \multicolumn{3}{|c|}{2.77} & \multicolumn{3}{|c|}{2.55} \\
\hline Number of stations & \multicolumn{3}{|c|}{20} & \multicolumn{3}{|c|}{24} & \multicolumn{3}{|c|}{33} \\
\hline
\end{tabular}

$\mathrm{B}=$ Unstandardized coefficient.

Beta=Standardized coefficient. 
Table 9: Regression results of 6 variables nocturnal climate models.

\begin{tabular}{|c|c|c|c|c|c|c|c|c|c|}
\hline \multirow{3}{*}{$\begin{array}{l}\text { Description } \\
\text { Variables }\end{array}$} & \multicolumn{3}{|c|}{ Clear sky periods } & \multicolumn{3}{|c|}{ Partially cloudy periods } & \multicolumn{3}{|c|}{ Cloudy periods } \\
\hline & \multicolumn{2}{|c|}{ Coefficient } & \multirow[t]{2}{*}{ Significant level } & \multicolumn{2}{|c|}{ Coefficient } & \multirow[t]{2}{*}{ Significant level } & \multicolumn{2}{|c|}{ Coefficient } & \multirow[t]{2}{*}{ Significant leve } \\
\hline & $\mathrm{B}$ & Beta & & $\mathrm{B}$ & Beta & & $\mathrm{B}$ & Beta & \\
\hline Surface albedo (SA) & -6.81 & -0.47 & $1.4 \mathrm{E} 06$ & -5.50 & -0.45 & $5.6 \mathrm{E}-06$ & -3.66 & -0.43 & $2.07 \mathrm{E}-05$ \\
\hline Aspect ratio (AR) & 0.17 & 0.09 & 0.187 & 0.10 & 0.06 & 0.391 & 0.03 & 0.03 & 0.693 \\
\hline Thermal mass (TM) & $3.7 \mathrm{E}-04$ & 0.05 & 0.516 & $3.1 \mathrm{E}-04$ & 0.05 & 0.526 & $4.4 \mathrm{E}-04$ & 0.10 & 0.210 \\
\hline Green density ratio (GDR) & -0.73 & -0.20 & 0.071 & -0.49 & -0.16 & 0.161 & -0.29 & -0.14 & 0.251 \\
\hline Plan density ratio (PDR) & -0.18 & -0.04 & 0.793 & -0.04 & -0.01 & 0.949 & -0.21 & -0.08 & 0.627 \\
\hline Fabric density ratio (FDR) & 0.99 & 0.27 & 0.036 & 0.95 & 0.32 & 0.020 & 0.85 & 0.41 & 0.004 \\
\hline Constant & 3.29 & & & 2.59 & & & 1.45 & & \\
\hline $\mathbf{R}^{2}$ & \multicolumn{3}{|c|}{0.80} & \multicolumn{3}{|c|}{0.79} & \multicolumn{3}{|c|}{0.77} \\
\hline F static & \multicolumn{3}{|c|}{46.83} & \multicolumn{3}{|c|}{42.49} & \multicolumn{3}{|c|}{39.64} \\
\hline Critical ' $F$ ' static & \multicolumn{3}{|c|}{2.34} & \multicolumn{3}{|c|}{2.34} & \multicolumn{3}{|c|}{2.34} \\
\hline Number of stations & \multicolumn{3}{|c|}{77} & \multicolumn{3}{|c|}{77} & \multicolumn{3}{|c|}{77} \\
\hline
\end{tabular}

$\mathrm{B}=$ Unstandardized coefficient.

Beta=Standardized coefficient. 
Table 10: Regression results of 6 variables nocturnal models of 3 zones during partially cloudy period.

\begin{tabular}{|c|c|c|c|c|c|c|c|c|c|}
\hline Description & \multicolumn{3}{|c|}{ Core area (zone-1) } & \multicolumn{3}{|c|}{ Urban area (zone-2) } & \multicolumn{3}{|c|}{ Semi-urban area (zone-3) } \\
\hline \multirow[t]{2}{*}{ Variables } & \multicolumn{2}{|c|}{ Coefficient } & \multirow[t]{2}{*}{ Significant level } & \multicolumn{2}{|c|}{ Coefficient } & \multirow[t]{2}{*}{ Significant level } & \multicolumn{2}{|c|}{ Coefficient } & \multirow[t]{2}{*}{ Significant leve } \\
\hline & B & Beta & & $\mathrm{B}$ & Beta & & $\mathrm{B}$ & Beta & \\
\hline Surface albedo (SA) & -6.31 & -0.53 & 0.016 & 0.32 & 0.03 & 0.892 & -4.42 & -0.52 & 0.017 \\
\hline Aspect ratio (AR) & 0.02 & 0.04 & 0.858 & -0.04 & -0.06 & 0.769 & -1.89 & -0.31 & 0.165 \\
\hline Thermal mass (TM) & $-1.7 \mathrm{E}-04$ & -0.10 & 0.662 & 4.9E-04 & 0.10 & 0.642 & $2.0 \mathrm{E}-03$ & 0.19 & 0.323 \\
\hline Green density ratio (GDR) & 0.35 & 0.22 & 0.351 & -1.37 & -0.63 & 0.018 & -0.18 & -0.08 & 0.83 \\
\hline Plan density ratio (PDR) & 0.52 & 0.33 & 0.334 & -0.70 & -0.28 & 0.458 & -3.38 & -0.73 & 0.188 \\
\hline Fabric density ratio (FDR) & 0.50 & 0.50 & 0.043 & 0.81 & 0.43 & 0.254 & 5.68 & 1.20 & 0.038 \\
\hline Constant & 3.282 & & & 1.81 & & & 0.42 & & \\
\hline $\mathbf{R}^{2}$ & \multicolumn{3}{|c|}{0.75} & \multicolumn{3}{|c|}{0.60} & \multicolumn{3}{|c|}{0.65} \\
\hline F static & \multicolumn{3}{|c|}{6.41} & \multicolumn{3}{|c|}{4.20} & \multicolumn{3}{|c|}{7.97} \\
\hline Critical ' $F$ ' static & \multicolumn{3}{|c|}{2.95} & \multicolumn{3}{|c|}{2.77} & \multicolumn{3}{|c|}{2.55} \\
\hline Number of stations & \multicolumn{3}{|c|}{20} & \multicolumn{3}{|c|}{24} & \multicolumn{3}{|c|}{33} \\
\hline
\end{tabular}

$\mathrm{B}=$ Unstandardized coefficient.

Beta=Standardized coefficient. 